\title{
Treatment and Effect of Loess Metro Tunnel under Surrounding Pressure and Water Immersion Environment
}

\author{
Lixin Wang, ${ }^{1,2}$ Chenghan Li, ${ }^{3}$ Junling Qiu $\mathbb{D}^{3},{ }^{3}$ Ke Wang, ${ }^{2}$ Tong Liu $\mathbb{D}^{4},{ }^{4}$ and Heng $\mathrm{Li}^{3}$ \\ ${ }^{1}$ State Key Laboratory of Rail Transit Engineering Informatization, China Railway First Survey and Design Institute Group Co., Ltd., \\ Xi'an, China \\ ${ }^{2}$ Institute of Geotechnical Engineering, Xi'an University of Technoloy, Xi'an, China \\ ${ }^{3}$ School of Highway, Chang'an University, Xi'an, China \\ ${ }^{4}$ School of Science, Xi'an University of Architecture and Technology, Xi'an, China
}

Correspondence should be addressed to Junling Qiu; junlingqiu@chd.edu.cn and Tong Liu; liutong@xauat.edu.cn

Received 4 February 2020; Revised 5 May 2020; Accepted 7 May 2020; Published 13 June 2020

Academic Editor: Andrew H. Manning

Copyright (C) 2020 Lixin Wang et al. This is an open access article distributed under the Creative Commons Attribution License, which permits unrestricted use, distribution, and reproduction in any medium, provided the original work is properly cited.

\begin{abstract}
It is possible to pass through a collapsible loess stratum during metro tunneling. When the surrounding potential water sources with pressure are induced by external influences, the tunnel structure will be influenced in the affected area of loess collapsibility. To deal with the water inrush disaster of the tunnel in a collapsible loess stratum, the mechanism of grouting diffusion in the loess stratum is analyzed. It is found that the main influencing factors of the grouting effect are the radius of the grouting ring and the permeability coefficient of the grouting ring. Then, based on the water inrush section of a metro tunnel in Xi'an city, China, the treatment effect of the project is compared and analyzed through field tests, field monitoring, and finite element simulation. The results show that the water pressure at the measuring point of the tunnel vault is reduced by $4 \mathrm{MPa}$; the maximum and the minimum principal stresses at the top of the segment lining increased by $34.9 \mathrm{kPa}$ and $8.8 \mathrm{kPa}$, respectively, which is less than the increase without grouting; and the maximum displacement of the surrounding rock is reduced by $19 \mathrm{~mm}$. The plastic area produced by local water source infiltration is about $62 \%$ of that before grouting. The treatment measures of grouting in the tunnel are safe and effective. This study is of valuable meaning for the treatment of water inrush disaster of a loess tunnel under the water environment.
\end{abstract}

\section{Introduction}

Loess is mainly distributed in the arid and semiarid areas in the northern hemisphere and South America and New Zealand in the southern hemisphere, and it is most widely distributed in Asia [1]. Compared with other soils, loess has a special structure and water sensitivity: (1) the joint fissure is developed, the mesostructure is porous, and the wet-dry strength is significantly different; (2) most of them have strong collapsibility, and they will soften and deform in water. Therefore, the change of water environment makes it is easy to induce engineering disaster, and loess disaster easily occurs under the influence of human engineering activity [2]. But with the rapid development of urban metro construction in central and western China, it is inevitable to build metro tunnels in the collapsible loess area. If the potential confined water around the subway tunnel leaks due to external influ- ence, water pressure will act on the surrounding rock, and the surrounding rock in some areas will be immersed in water, which makes the surrounding rock saturated. It will form the surrounding pressure and water-soaking environment. The loess collapsibility will result. The leakage process of the loess local water source is mainly divided into three stages: local wet collapse stage, migration channel development stage, and stable infiltration stage. On the one hand, the water pressure directly acts on the tunnel structure; on the other hand, it permeates through the surrounding rock of the tunnel, which leads to the increase of the sliding force of the soil around the tunnel and the failure of the soil structure under the action of the seepage pressure and induces the displacement of the tunnel structure. Thus, the tunnel structure in the collapsible loess area is affected to some extent [2-7]. In the past 10 years, Xi'an city, as a key development city in central and western China, has built a large number 


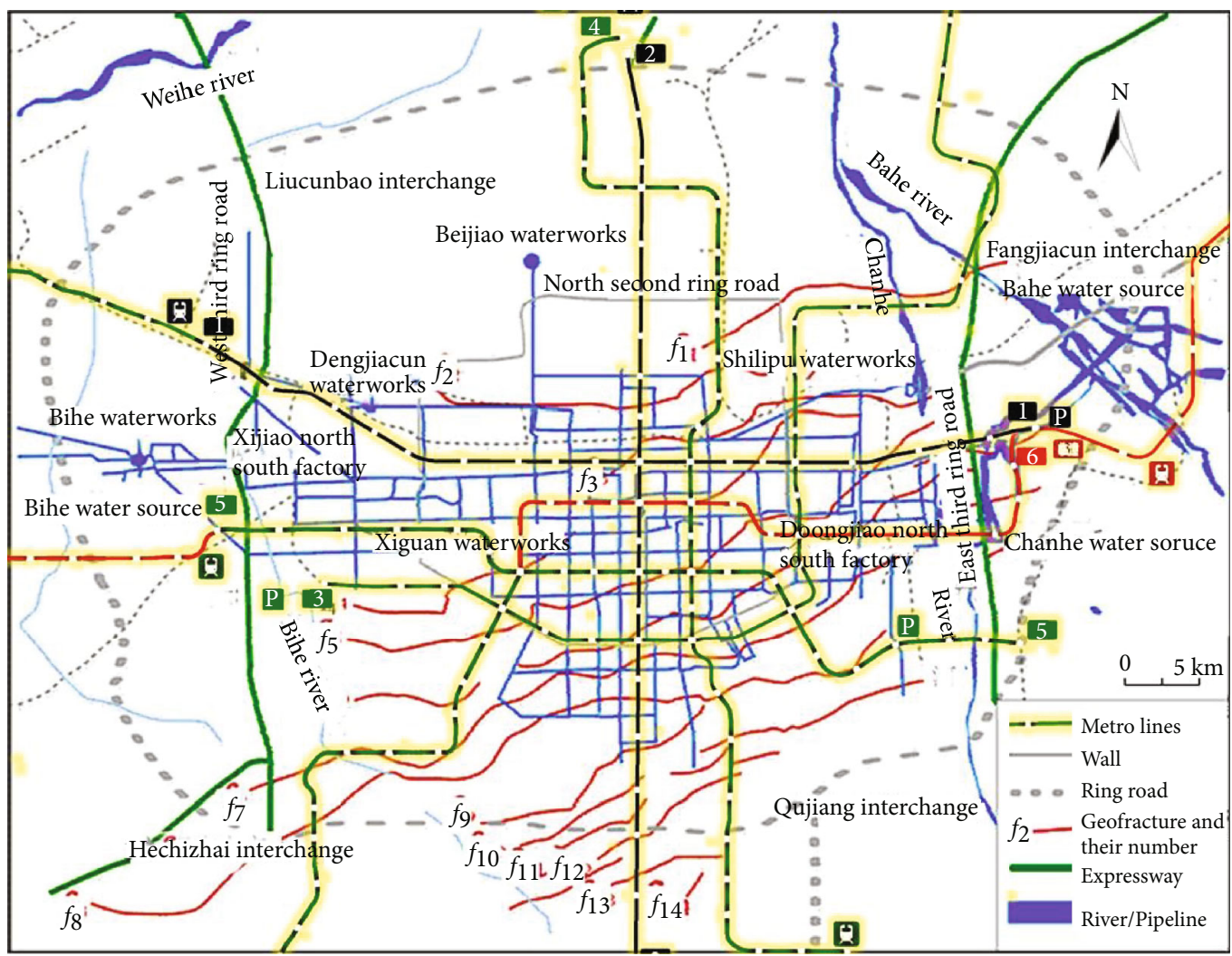

FIgURE 1: Underground pipeline network, ground fissure distribution, and metro planning in Xi'an City, China.

of metro projects in the loess stratum. According to the line planning of the Xi'an metro, a large number of ground fissures need to be crossed, as shown in Figure 1 [8-10]. The disturbance of tunnel construction will lead to large stratum deformation. According to the statistical data, the early municipal water pipeline materials are cement pipes and ceramic pipes, and their mechanical properties are relatively poor. When the pipelines are slightly disturbed, they easily break and leak. As a result, the leakage of urban pipelines will easily lead to large-scale collapsibility of the loess strata and water inrush accidents [11-13]. Figure 2 shows a typical tunnel water inrush accident.

To solve the influence of the leaking of tunneling or underground structures on the structure and surroundings, scholars have done a lot of research. Liu et al. [14] presented a prediction approach for time-dependent groundwater inflow into a tunnel in both anisotropic and isotropic confined aquifers, which was verified by actual engineering. To evaluate the influence of foam conditioning on groundwater inflow at the shield tunnel cutting face, Liu et al. [15] studied the three critical variables of the maximum foam infiltration distance, the critical infiltration distance, and the hydraulic conductivity of foam-conditioned soil or rock fissure by the force-equilibrium principle. And given the seepage problem of deep foundation pit excavation, Wu et al. [16] analyzed the seepage effect of the waterproof curtain by using a three-dimensional fluid-structure coupling finite element model. In practical engineering, the grouting method is often adopted to reinforce the loess stratum. At present, scholars have made abundant achievements in the study of grouting reinforcement of tunnel-surrounding rock. Giuseppe et al. [17] studied the effect of single and double liquid jet grouting on the mechanical properties of sand and cohesive soil through two field tests. Zhang et al. [18], through field measurement and numerical simulation, analyzed the influence of grouting treatment on reducing tunnel deformation, to solve the problem of large deformation of shield tunnel in soft soil. Akin et al. [19] used standard penetration tests (SPT) and multichannel analysis of surface waves (MASW) to study the modification of soil properties in the compression zone after jet-grouting in sandy and clayey soils. And based on the Hokusatsu tunnel, Gong et al. [20] proposed a multiple grouting method to solve the water seepage problem of the tunnel under the condition of high-pressure water.

At present, significant achievements have been made in the control and treatment of tunnel leakage. However, due to the particular engineering properties and hydrodynamic pressure of local water sources in the loess area, the formation mechanism, genesis mechanism, disaster mode, and evolution process of water inrush disaster far from the tunnel face are different from those of other regions and other geotechnical engineering disasters. The theory and technology of disaster prevention and control cannot use the existing theory and technology, so it is necessary to study the treatment mechanism and reinforcement effect of surrounding rock under instantaneous external water pressure in the collapsible loess area. Therefore, the diffusion calculation model is established, and the diffuse mechanism of grouting 


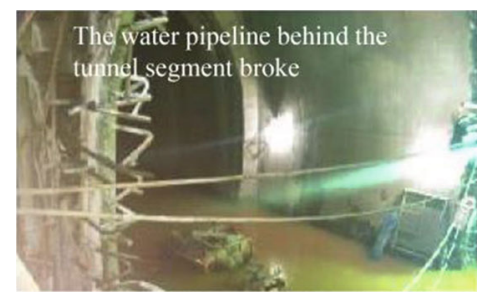

(a)

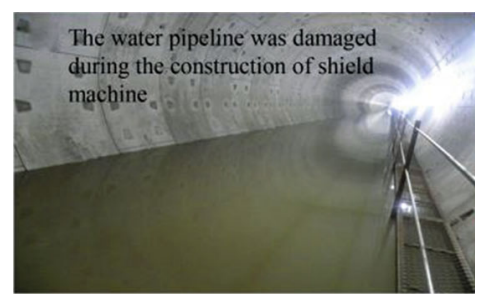

(c)

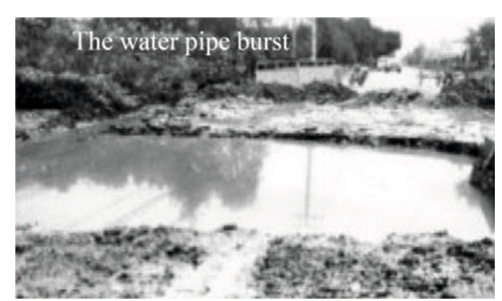

(b)

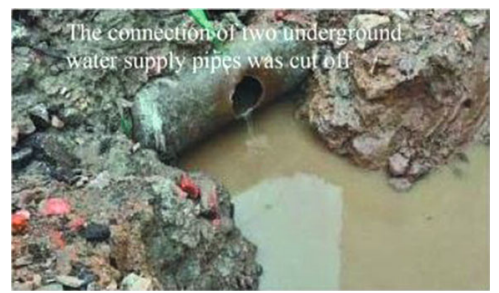

(d)

Figure 2: Water inrush accidents in metro tunnel: (a) Xi'an Metro Line 1, (b) Fuzhou Metro Line 2, (c) Xi'an Metro Line 4, and (d) Wuhan Metro Line 7.

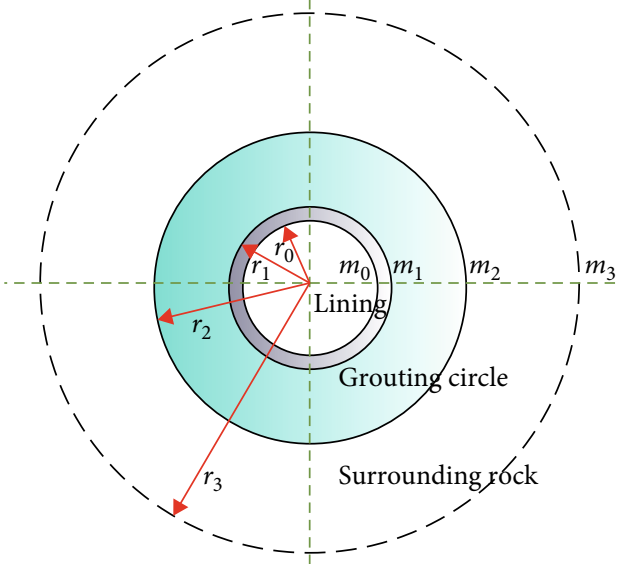

Figure 3: Diffusion calculation model.

reinforcement is studied in the loess stratum. According to the water inrush section of a metro tunnel in Xi'an, China, through field monitoring and finite element simulation, the effect of grouting reinforcement is analyzed. It is expected to provide theoretical support and safety guidance for metro safety construction and maintenance under the influence of the water environment in the future.

\section{Grouting Diffusion Calculation of Rich Water Loess Tunnel}

At present, grouting theory mainly analyzes the flow process of grouting fluid in the stratum and the deformation process of grouted medium. The quantitative relationship between grouting diffusion radius and grouting parameters and rheological parameters of grouting fluid is established [21]. Diffusion modes and mechanisms of grouting fluid in surrounding rocks with different properties are quite different [22]. The diffusion process of grouting fluid in the clay layer is generally bubbling compaction [23]. The grouting diffusion rein- forcement model in water-rich sand layers is divided into three main types: permeability mode, splitting-compaction mode, and permeability-splitting-compaction mode [21]. In deep alluvium, the grout is usually filled along the interface of soil and rock, and horizontal splitting is the primary method [24]. Under relatively high grouting pressure, the grout in the loess layer expands the original pore or fissures and forms new cracks and pores. Thus, the grouting effect of the saturated loess layer and the grout diffusion distance can be improved. The grout is mixed and rapidly coagulates in the pore or fissure, and a network of grouting veins in the soil is formed [25].

However, the research and development of loess grouting mechanisms are relatively backward and slow. The main reasons are as follows: (1) Because of the nonuniformity and uncertainty of the injected medium, such as the uncertainty and anisotropy of the permeability coefficient of soil, it is difficult to develop a theoretical method which can accurately predict the grouting process. (2) The variability of the grouting slurry itself and the influence of the medium on grouting slurry properties increase the difficulty of theoretical prediction $[26,27]$. Therefore, in engineering research, the grouting reinforcement zone is simplified and equivalent to a homogeneous stratum, which is simulated by improving the physical and mechanical parameters.

Through the investigation and analysis of a large number of tunnel structures under the water environment, the water pressure acting on the lining is related to a variety of factors, such as the surrounding rock, tunnel lining and external retaining ring, permeability coefficient, and water head [28, 29]. In the loess stratum, the heterogeneity and regional difference of the permeability coefficient of loess in the vertical and horizontal directions lead to the extremely complex spatial distribution of the slurry vein. It is difficult to quantify through theoretical analysis [25]. To highlight the relationship between water inflow and lining, grouting reinforcement ring, and surrounding rock, the grouting vein is simplified as a straight crack, and a simplified diffusion model is adopted 
$[30,31]$. The calculation model is shown in Figure 3. It can be assumed that the diffuse process of the loess medium is continuous, and the seepage of water in loess surrounding rock obeys Darcy's law.

As shown in Figure 3, a polar coordinate system is established. The direction of the tunnel axis is set to the $z$-axis, and the direction of the tunnel radius is set to the $r$-axis. The water head at each location of the tunnel and surrounding rock is $M$. Since the seepage of water in the surrounding rock obeys Darcy's law, based on the seepage continuity relation, the following equation can be obtained:

$$
\frac{1}{r} \frac{\partial}{\partial r}\left(r \frac{\partial M}{\partial r}\right)+\frac{1}{r^{2}} \frac{\partial^{2} M}{\partial \theta^{2}}+\frac{\partial^{2} M}{\partial z^{2}}=0
$$

For stable fluids, $\partial M / \partial z=0$, and according to symmetry, $\partial M / \partial \theta=0$; so by the integral method, the following formula can be obtained:

$$
r \frac{d M}{d r}=C
$$

Assuming that the water inflow at the water inrush section is $Q$, the permeability coefficient of different materials is $k$. By Darcy's law, the water inflow per linear meter of tunnel length can be obtained:

$$
Q=2 \pi k \frac{d m}{d r}
$$

According to the range of boundary conditions $r$ and $m$, the following formula can be obtained by the definite integral:

$$
\int_{m_{1}}^{m_{2}} d m=\frac{Q}{2 \pi k} \int_{r_{1}}^{r_{2}} \frac{d r}{r}
$$

In the range of surrounding rock, $k_{2}$ is set as the permeability coefficient of surrounding rock. $r_{2} \leq r \leq r_{3}$ and $m_{2} \leq$ $m \leq m_{3}$. At the water inrush section, the water inflow $Q_{2}$ through the surrounding rock is obtained as follows:

$$
Q_{2}=\frac{2 \pi k_{2}\left(m_{3}-m_{2}\right)}{\ln \left(r_{3} / r_{2}\right)} \text {. }
$$

In the range of the grouting reinforcement ring, $k_{1}$ is set as the permeability coefficient of the grouting body. $r_{1} \leq r \leq$ $r_{2}$ and $m_{1} \leq m \leq m_{2}$. The water inflow $Q_{1}$ through the grouting ring at the water inrush section is obtained as follows:

$$
Q_{1}=\frac{2 \pi k_{1}\left(m_{2}-m_{1}\right)}{\ln \left(r_{2} / r_{1}\right)}
$$

In the range of lining, $k_{0}$ is set as the permeability coefficient of the lining. $r_{0} \leq r \leq r_{1}$ and $m_{0} \leq m \leq m_{1}$. The water inflow $Q_{0}$ through the grouting ring at the water inrush section is obtained as follows:

$$
Q_{0}=\frac{2 \pi k_{0}\left(m_{1}-m_{0}\right)}{\ln \left(r_{1} / r_{0}\right)}
$$

Because the flow is the same in different cross-sections, there is $Q_{2}=Q_{1}=Q_{0}$. The following simultaneous equations are established:

$$
\frac{2 \pi k_{2}\left(m_{3}-m_{2}\right)}{\ln \left(r_{3} / r_{2}\right)}=\frac{2 \pi k_{1}\left(m_{2}-m_{1}\right)}{\ln \left(r_{2} / r_{1}\right)}=\frac{2 \pi k_{0}\left(m_{1}-m_{0}\right)}{\ln \left(r_{1} / r_{0}\right)} \text {. }
$$

The water inflow per linear meter of tunnel length $Q$ is as follows:

$$
Q=\frac{2 \pi\left(m_{3}-m_{0}\right) k_{2}}{\ln \left(r_{3} / r_{2}\right)+\left(k_{2} / k_{1}\right) \ln \left(r_{2} / r_{1}\right)+\left(k_{2} / k_{0}\right) \ln \left(r_{1} / r_{0}\right)}
$$

The water pressure behind the tunnel lining $p_{0}$ is as follows:

$$
p_{0}=\gamma_{w} m_{1}=\frac{\left(m_{3}-m_{0}\right) \gamma_{w} \ln \left(r_{1} / r_{0}\right)}{\ln \left(r_{1} / r_{0}\right)+\left(k_{0} / k_{2}\right) \ln \left(r_{3} / r_{2}\right)+\left(k_{0} / k_{1}\right) \ln \left(r_{2} / r_{1}\right)} .
$$

The water pressure on the outer surface of the grouting

$$
p_{1}=\gamma_{w} h_{2}=\gamma_{w} m_{0}\left(1-\frac{\ln \left(\left(m_{3}-m_{0}\right) / r_{2}\right)}{\left(k_{2} / k_{0}\right) \ln \left(r_{1} / r_{0}\right)+\left(k_{1} / k_{2}\right) \ln \left(r_{3} / r_{2}\right)+\ln \left(\left(m_{3}-m_{0}\right) / r_{2}\right)}\right) .
$$

According to the water pressure on the outer surface of the grouting reinforcement ring, the water pressure outside the grouting ring is related to the ratio of surrounding rock to the permeability coefficient of the reinforcement ring, the radius of the tunnel, the far head, and the grouting ring. For the water pressure acting on the lining, it is mainly reinforcement ring $p_{1}$ is as follows:

affected by the following aspects: (1) The seepage pressure on the lining is related to the lining thickness, water head, and other factors. (2) The seepage pressure on the lining is affected by the permeability coefficient of the surrounding rock, and the water pressure on the lining in the leaking area will increase significantly. (3) The seepage pressure on the 


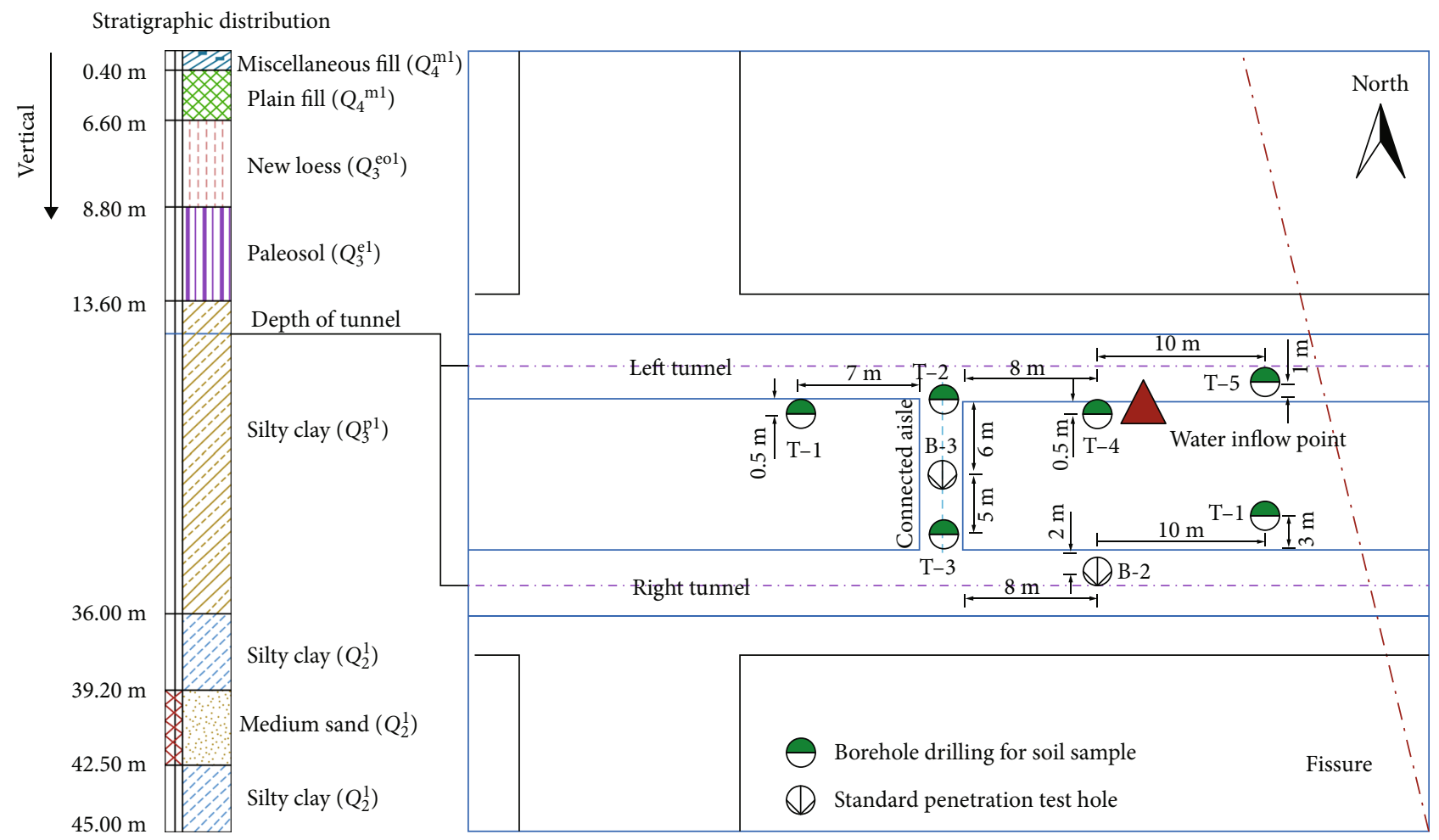

FIGURE 4: Selection of soil samples for the Xi'an metro tunnel.

TABLE 1: Main physical parameters of soil samples in tunnel site.

\begin{tabular}{lcccc}
\hline Main indicators & $\begin{array}{c}\text { Natural density } \\
\rho\left(\mathrm{g} \cdot \mathrm{cm}^{-3}\right)\end{array}$ & $\begin{array}{c}\text { Natural water content } \\
\omega(\%)\end{array}$ & $\begin{array}{c}\text { Saturation density } \\
\rho_{\text {sat }}\left(\mathrm{g} \cdot \mathrm{cm}^{-3}\right)\end{array}$ & $\begin{array}{c}\text { Saturated water content } \\
\omega_{\text {sat }}(\%)\end{array}$ \\
\hline Average value & 1.57 & 21.97 & 1.81 & $\begin{array}{c}\text { Air void } \\
n(\%)\end{array}$ \\
\hline
\end{tabular}

TABLE 2: Elastic modulus of loess with different water content and dry-wet cycle.

\begin{tabular}{lccccc}
\hline \multirow{2}{*}{ Cycle times } & \multicolumn{5}{c}{ Elastic modulus (MPa) } \\
& $\omega=0 \%$ & $\omega=5 \%$ & $\omega=15 \%$ & $\omega=25 \%$ & $\omega=34.09 \%$ \\
\hline 0 & 311.23 & 31.56 & 7.53 & 4.84 & 3.36 \\
2 & 215.64 & 28.67 & 7.34 & 4.16 & 3.69 \\
4 & 226.82 & 24.36 & 7.36 & 3.84 & 2.79 \\
6 & 211.42 & 23.76 & 6.68 & 3.46 & 2.76 \\
\hline
\end{tabular}

lining is affected by the permeability coefficient of the reinforcing ring. As the reinforcing ring becomes thicker, the permeability coefficient decreases and the water pressure acting on the lining decreases accordingly.

\section{Engineering Case Analysis}

3.1. General Situation of Engineering. The shield construction method was adopted in a tunnel of Xi'an metro affected by pipeline leakage. The average depth of the tunnel is about $14.0 \mathrm{~m}$, the distance between the bottom of the tunnel and the surface is about $20.0 \mathrm{~m}$, and the distance between the left and right lines of the shield tunnel is $12.0 \mathrm{~m}$. The tunnel is located in the silty clay layer. From the surface down, each stratum is mainly miscellaneous fill, plain fill, new loess (collapsible), ancient soil, silty clay, medium sand, and old loess. To provide reliable experimental data for the follow-up model test, the physical and mechanical properties of loess in saturated, unsaturated, and dry-wet cycles in the Xi'an metro tunnel site are studied. The location of soil sample selection is shown in Figure 4. Besides, direct shear tests and uniaxial compression tests are carried out on the soil samples taken at the tunnel depth [32-36]. Test data are shown in Tables 1 and 2 and Figure 5.

The construction process of the connecting passage \#1 of the metro tunnel is from left to right. The excavation of the connecting passage and the construction of the primary lining is divided into upper and lower pilot tunnels. When the excavation of the upper is completed, the underground water pipeline near the tunnel breaks down, and the local dynamic water source leaks out. At this time, the tunnel section about $10 \mathrm{~m}$ to the east of the connecting channel is greatly affected. There is water inrush behind the segment near the bottom of the tunnel. The location and condition of water inrush are shown in Figure 6. The mileage pile number of the water inrush point is ZDK20+616. After the leakage occurred, the surface, in the east of the cross of Yanta north road and Jiandong street, of the tunnel inrush section subsided. Then, the 


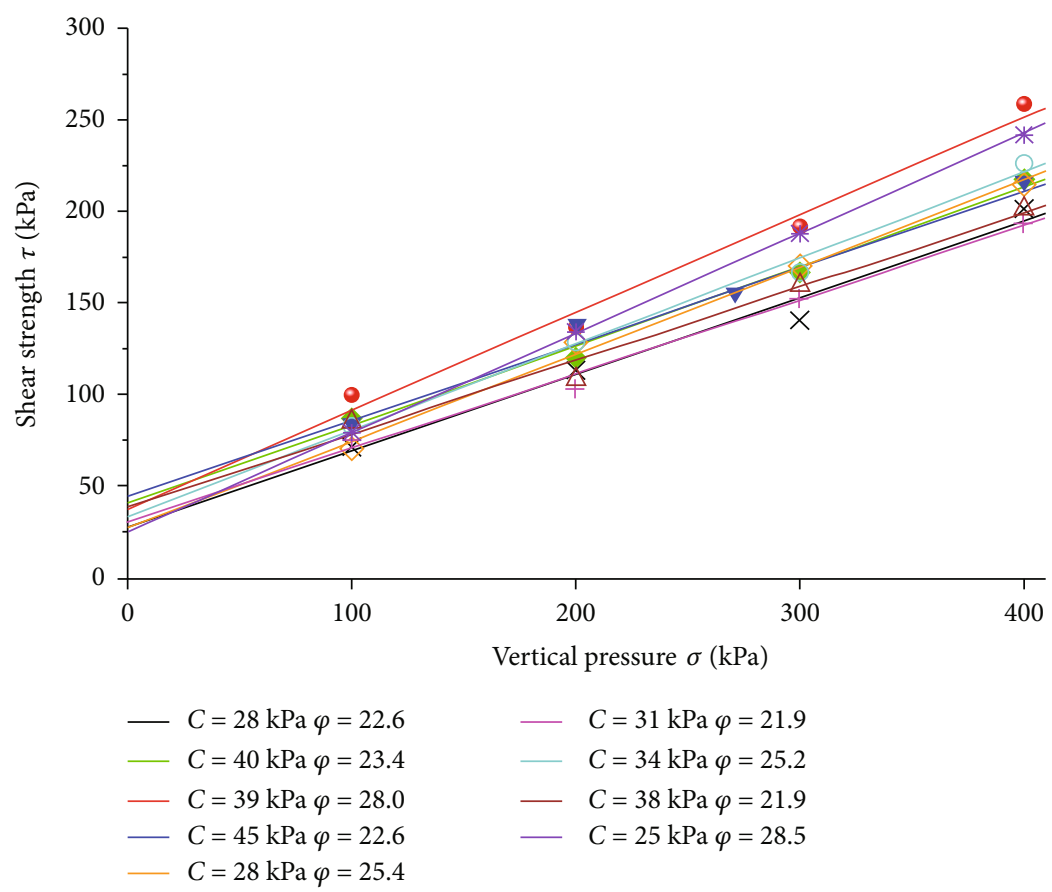

Figure 5: Direct shear test results of field soil samples.

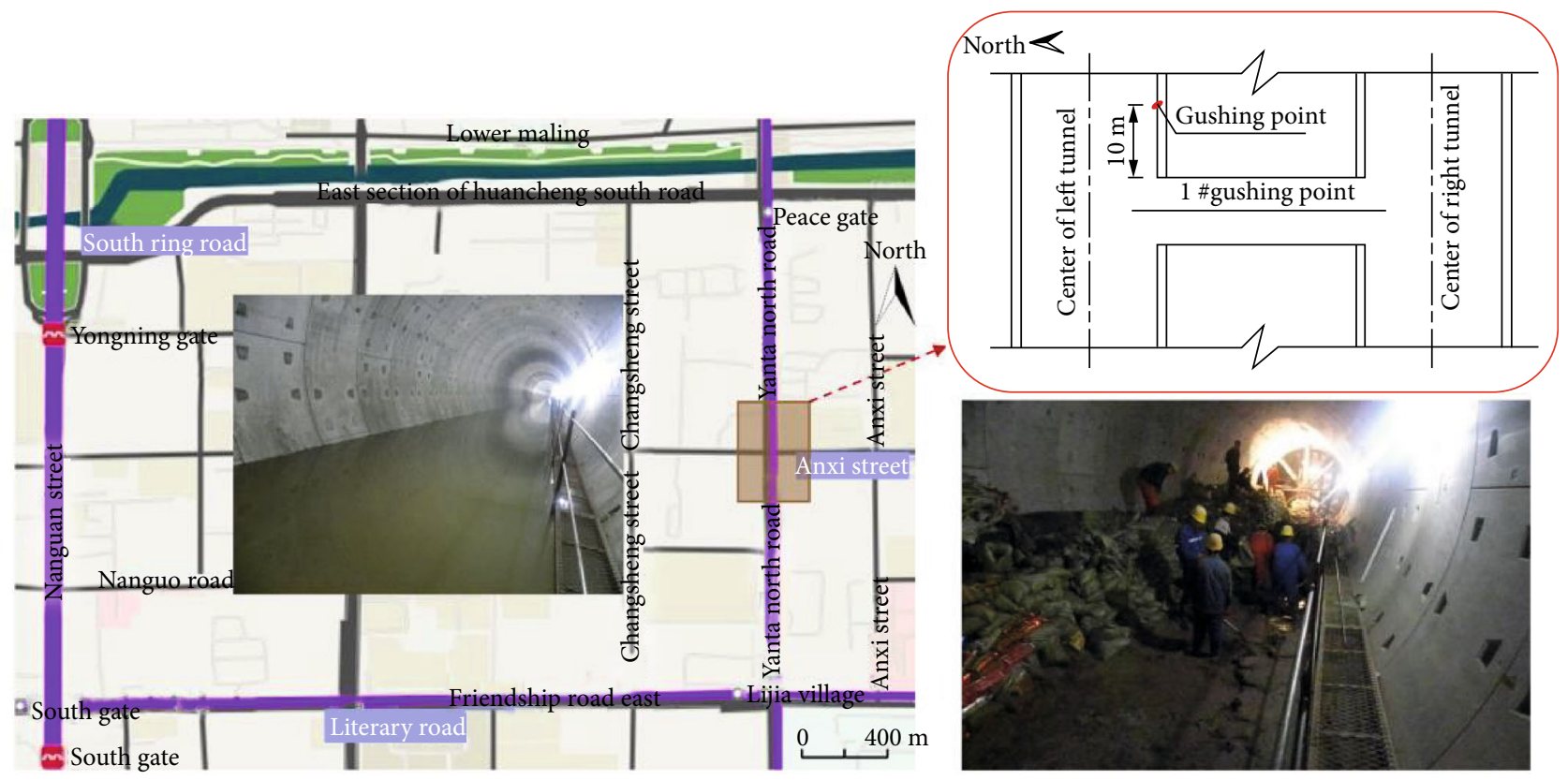

FIgURE 6: Water inrush position.

tap pipe valves are closed one after another. The ground above the tunnel collapsed, and the scope of the collapse was further expanded. The collapsed area is about $20 \mathrm{~m}$ long, $12 \mathrm{~m}$ wide, and $6.5 \mathrm{~m}$ deep. The ground collapse is further extended to the east, and the scope is increased to about $20 \mathrm{~m}$ long and $20 \mathrm{~m}$ wide. When there is water inrush behind the segment, the deepest water level in the tunnel is about $2.5 \mathrm{~m}$. After field monitoring, the flow rate is about $350 \mathrm{~m}^{3} / \mathrm{h}$, and the total water inflow is up to $120,000 \mathrm{~m}^{3}$.
There are many commercial and residential buildings around the water inrush section of the tunnel, and underground pipelines are complex. This collapse resulted in the breakage of water pipes, sewage pipes, and natural gas pipes. A summary of the affected pipelines is shown in Table 3. According to the monitoring data, the maximum settlement of buildings around the collapsed area is $2.9 \mathrm{~mm}$, and the deformation of buildings is small. Water inrush disaster also caused ground subsidence, which had a great impact on 
TABLE 3: Summary of affected water supply and drainage pipelines.

\begin{tabular}{lcccc}
\hline Name & Pipe diameter & Burying depth $(\mathrm{m})$ & Texture of material & Influence situation \\
\hline Rain pipe & DN1000 & 5.1 & Brick construction & Truncation \\
Rain pipe & DN1500 & 5.6 & Concrete & Truncation \\
Rain pipe & DN300 & 0.5 & Concrete & Truncation \\
Tap water pipe & DN400 & 1.7 & Ductile iron pipe & Have been relocated \\
Sewage pipe & DN500 & 3.5 & Concrete & Temporary plugging \\
Tap water pipe & DN1000 & 1.5 & Concrete & Adding plug \\
\hline
\end{tabular}

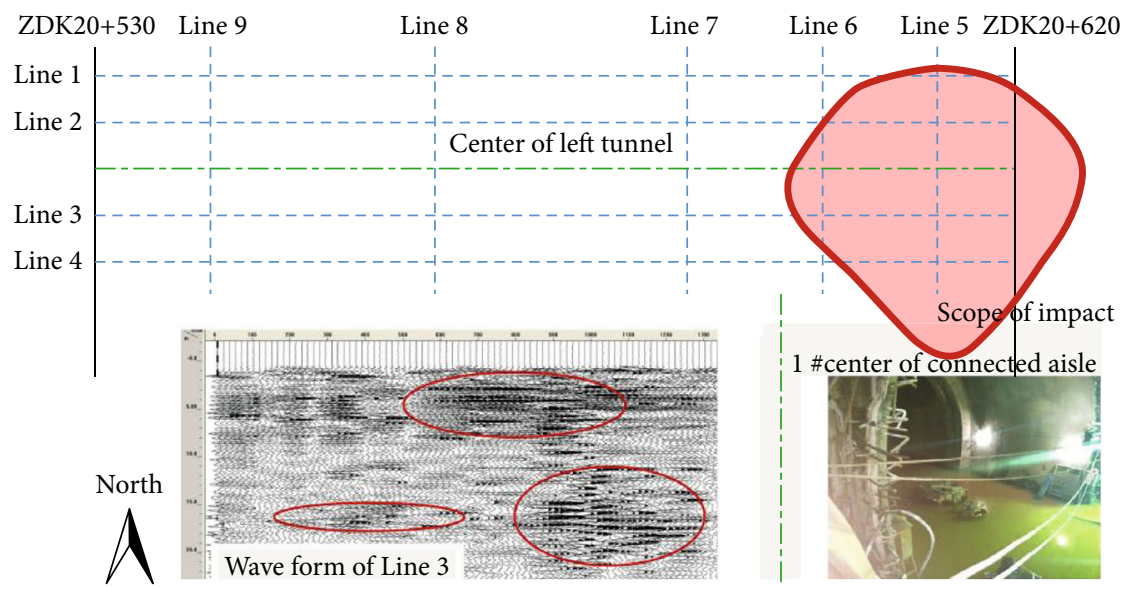

FIGURE 7: GPR survey line layout and influencing range of water inrush.

ground traffic. Besides, through on-site monitoring statistics, it is found that the water inrush disaster also causes deformation, local damage, and dislocation of the right shield tunnel segment. The maximum value of dislocation reaches $4 \mathrm{~cm}$.

\subsection{Influence Scope and Deformation Monitoring of Water Inrush Accident}

3.2.1. Detection of Stratum Influencing Range. Surface subsidence occurred in the range of the ZDK20+530-ZDK20 +620 after the water inrush disaster. The scope of subsidence is mainly concentrated on the left tunnel. Subsequently, ground penetrating radar (GPR) was used to detect geological conditions on the ground surface. The antenna frequency is $100 \mathrm{MHz}$, and the ground survey line arrangement is shown in Figure 7. The results show that the lower strata within the range of 2-4 $\mathrm{m}$ and $13-23 \mathrm{~m}$ in the ZDK20+590ZDK20+620 section have a strong reflection. It is presumed that the strong reflection area of the lower stratum is rich in water or not compact. In this section, there is a fracture in the stratum phase axis, which is presumed to be caused by the uneven settlement of the lower stratum of the pavement. The ZDK20+530-ZDK20+590 section does not have an apparent strong reflection signal. The phase axis is continuous, and the lower strata of this section are continuous without abnormality. According to all survey lines, the lower strata are unevenly settled and partly not compact or rich in water within the range of ZDK20+590-ZDK20+620. The lower strata of line 5 , line 6 , line 7 , and line 8 are unevenly settled and partly not compact or rich in water. The lower strata of line 4 and line 9 are uniformly and continuously distributed without apparent anomalies. It is inferred that the affected areas of water inrush on the stratum are shown in Figure 7.

3.2.2. Displacement Monitoring and Analysis. After water inrush, the frequency of monitoring in the tunnel is increased immediately, especially for convergence deformation, vault settlement, and surface settlement; it is raised to every 2 hours. Concurrently, the collected data are analyzed and evaluated in time. The layout of test sections and measuring points are as follows: 7 sections are set up for the tunnel vault settlement test, 14 sections are set for the tunnel convergence deformation test, and 8 rows of measuring lines are set for the surface settlement test. The specific field monitoring scheme is shown in Figure 8, and the main monitoring results are shown in Figures 9 and 10.

Although the L3 monitoring point near the overpass is far from the shield tunnel, it is also affected by water leakage from pipes and grouting treatment. The ground loss caused by soil erosion leads to the increased subsidence of the ground, which is about $4 \mathrm{~mm}$. With the continuation of grouting, the surrounding rock is squeezed by grouting pressure, which forces the ground to rise. The effect of soil erosion is compensated, and the ground rose about $8 \mathrm{~mm}$. L1, $\mathrm{M} 1$, and M2 monitoring points are close to the tunnel. The surface settlement in this area is obvious, and the settlement reaches its maximum value in the later period. The surface settlement caused by water inrush is about $15 \mathrm{~mm}$. Subsequently, the surface quickly floated up, resulting in a maximum floatation of about $20 \mathrm{~mm}$. Therefore, according to 


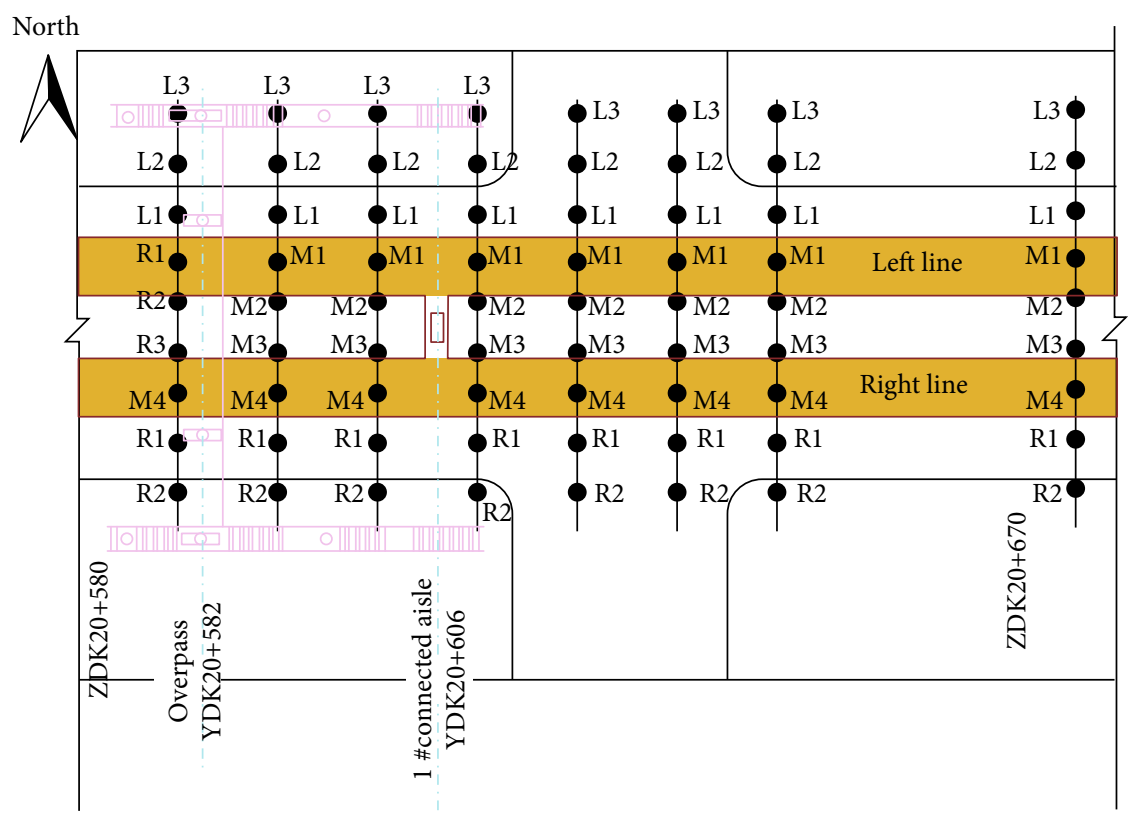

FIGURE 8: Displacement monitoring point arrangement.

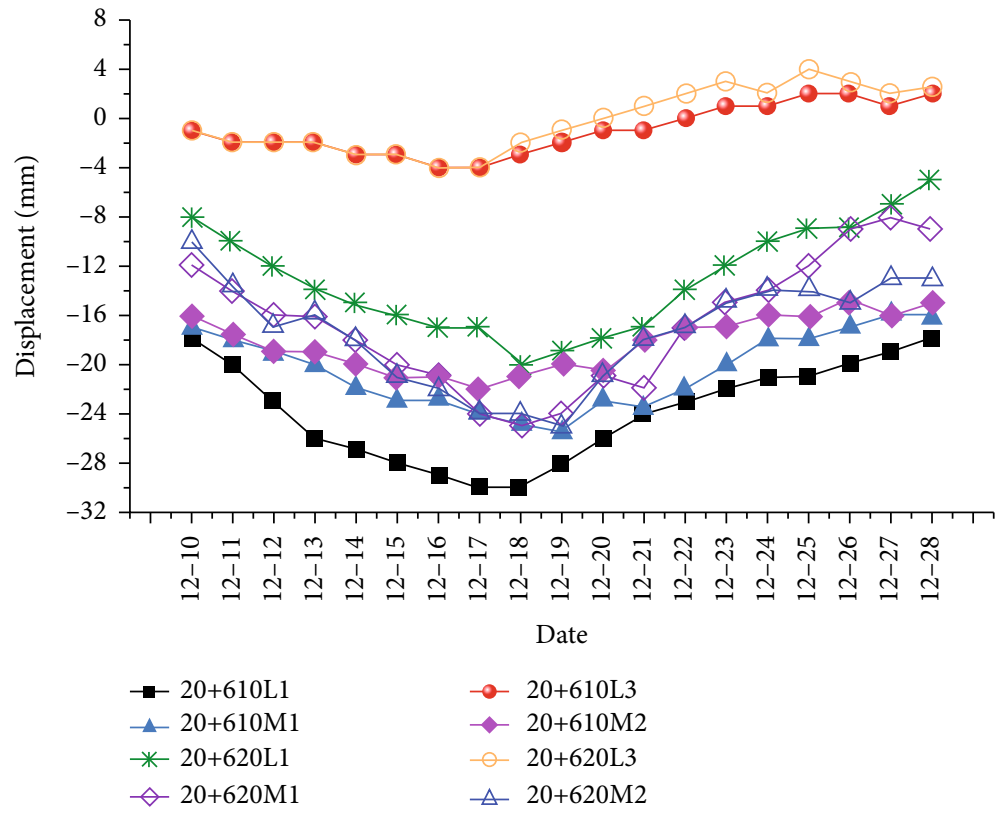

FiguRE 9: Surface cumulative subsidence curve.

the analysis, the main function of the initial stage of grouting is to block up water and water transport channels and to minimize the ground loss caused by soil erosion. The later effect is mainly to compensate for the settlement caused by water inrush and compact the soil.

Some test sections cannot be monitored because of the limitation of site conditions. But through the analysis of the monitoring data, it can be seen that the tunnel lining near the water source is tensioned on the outside, compressed on the inside, and subjected to the negative moment at the initial stage of water inrush. Due to the existence of collapsible voids, the segment lacks enough foundation support, which caused the segments to keep moving outward and the convergence to increase continuously. [37, 38]. With the continuous grouting, due to the role of grouting pressure, the loss of foundation reaction is compensated, so that the convergence is gradually reduced. For the later stage of grouting, the grouting pressure acting on the segment exceeds the foundation reaction. The inner side of the segment was pulled, and the outer side was pressed. The structure bears additional stress, and the segment moves to the inside [39, 40]. After grouting, the accumulated transverse displacement of segments reaches $4.5 \mathrm{~cm}$. When the water inrush accident occurred, the segment subsided, and it gradually began to rise 


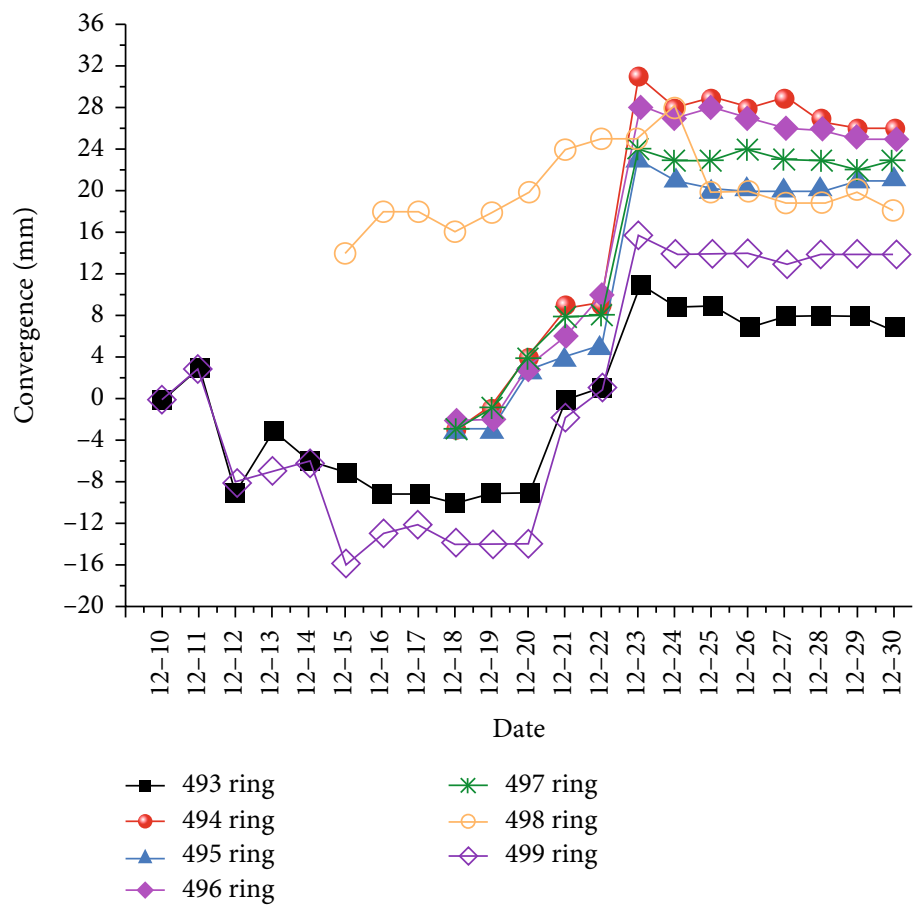

(a)

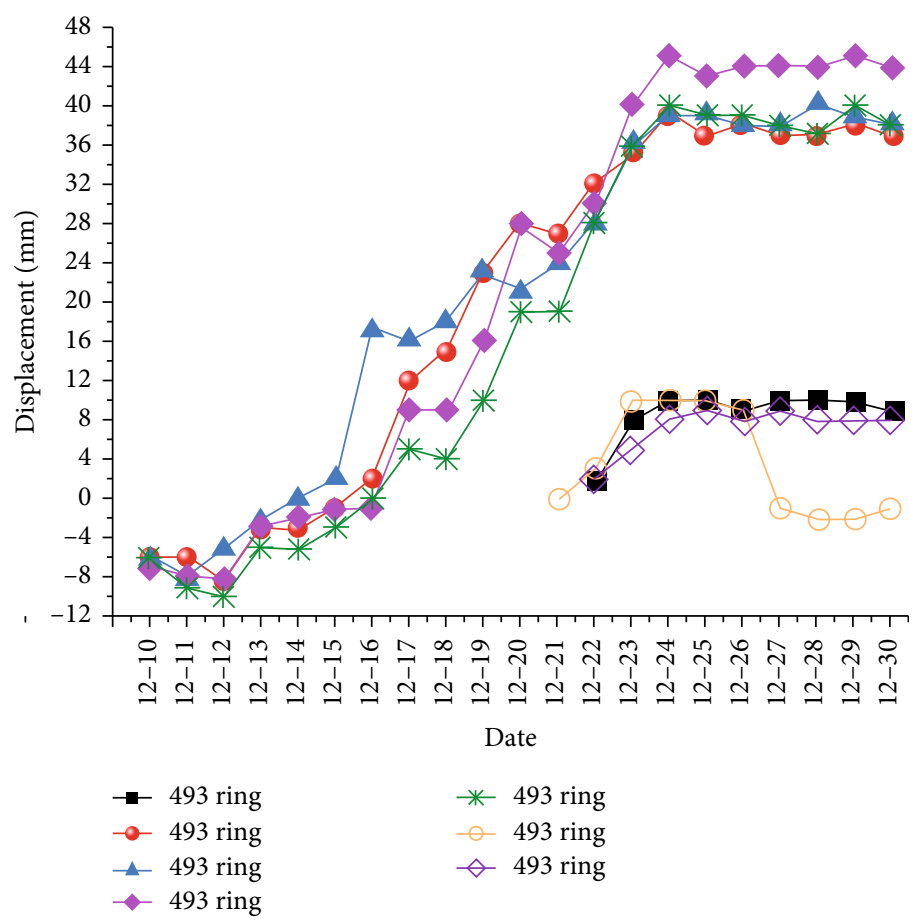

(b)

Figure 10: Cumulative deformation curve of the tunnel: (a) accumulated convergence; (b) accumulated settlement.

after grouting for 2 days. Subsequently, it rose faster until the grouting stopped, and the maximum rising displacement was $5.5 \mathrm{~cm}$.

\subsection{Treatment Measures and Effect Analysis}

3.3.1. Treatment Measures. The water inrush accident causes the tunnel support to crack, deform, and empty. And given the influence of soil erosion on surrounding buildings and forming tunnels, it is necessary to fill the stratum with grouting in the tunnel. Generally, the treatment steps of "stable collapse, internal and external cooperation, grouting reinforcement, filling holes" should be followed [41-43]. During the treatment, it is necessary to protect the formed tunnel, so a temporary steel support is added to the shield tunnel before grouting [44-46]. Also, a water inrush caused holes behind 


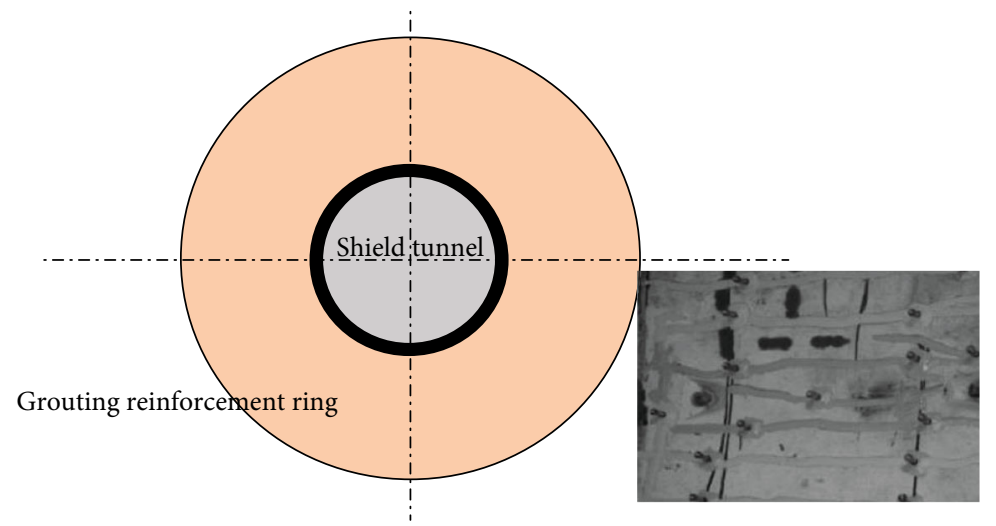

FIGURE 11: Diagram of grouting reinforcement in the tunnel.

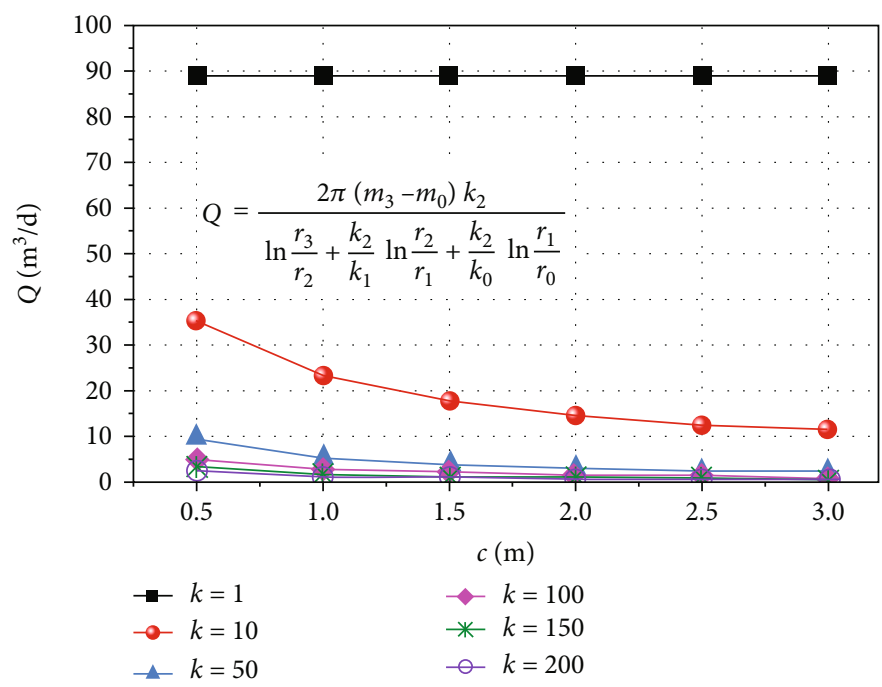

FIGURE 12: The relationship curve between the water inflow of the tunnel and the thickness of the reinforcement ring.

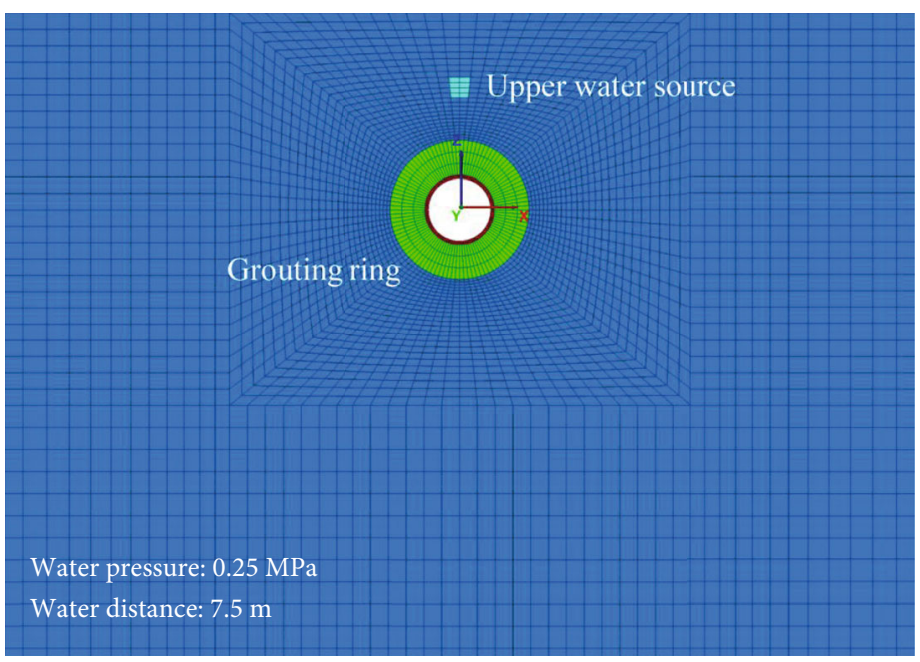

FIGURE 13: Grouting calculation model.

the primary lining on the east side of the tunnel. To solve this problem, grouting reinforcement is adopted to repair it. Small conduits are used from the east side wall of the tunnel for grouting, backfilling holes, and water inrush passages.
The tunnel vault, side wall, and arch foot are grouted. The grouting holes are arranged in a quincunx shape with a spacing of $1 \mathrm{~m}$. The cement-sodium silicate binary slurry with a ratio of $1: 1$ is used, and the grouting pressure is $0.3 \mathrm{MPa}$ - 
TABLE 4: Physical and mechanical parameters of the reinforcement ring.

\begin{tabular}{lcccccccc}
\hline Material & $\begin{array}{c}\text { Thickness } \\
(\mathrm{cm})\end{array}$ & $\begin{array}{c}\text { Density } \\
\left(\mathrm{kg} / \mathrm{m}^{3}\right)\end{array}$ & $\begin{array}{c}\text { Poisson's } \\
\text { ratio }\end{array}$ & $\begin{array}{c}\text { Cohesion } \\
(\mathrm{kPa})\end{array}$ & $\begin{array}{c}\text { Permeability } \\
\text { coefficient }(\mathrm{cm} / \mathrm{s})\end{array}$ & $\begin{array}{c}\text { Internal friction } \\
\text { angle }\left({ }^{\circ}\right)\end{array}$ & $\begin{array}{c}\text { Bulk modulus } \\
(\mathrm{MPa})\end{array}$ & $\begin{array}{c}\text { Shear modulus } \\
(\mathrm{MPa})\end{array}$ \\
\hline Grouting & 300 & 1990 & 0.2 & 70 & $4.06 \times 10^{6}$ & 28.15 & $2 \times 10^{4}$ & $1.5 \times 10^{4}$ \\
\hline
\end{tabular}

TABLE 5: Analysis of pore water pressure at measuring points ( $\mathrm{kPa})$.

\begin{tabular}{lcccccccccccc}
\hline Measure point & 1 & 2 & 3 & $\mathrm{~A}$ & $\mathrm{~B}$ & $\mathrm{C}$ & $\mathrm{D}$ & $\mathrm{E}$ & $\mathrm{F}$ & $\mathrm{G}$ & $\mathrm{H}$ \\
\hline Section \#1 & 215.1 & 103.02 & 58.77 & 0 & 0 & 1.95 & 31.23 & 50.59 & 31.24 & 1.95 & 0 \\
Section \#2 & 41.65 & 30.33 & 20.31 & 0 & 0 & 0 & 6.62 & 18.44 & 6.62 & 0 & 0 \\
Section \#3 & 0 & 0 & 0 & 0 & 0 & 0 & 0 & 0 & 0 & 0 & 0 \\
\hline
\end{tabular}

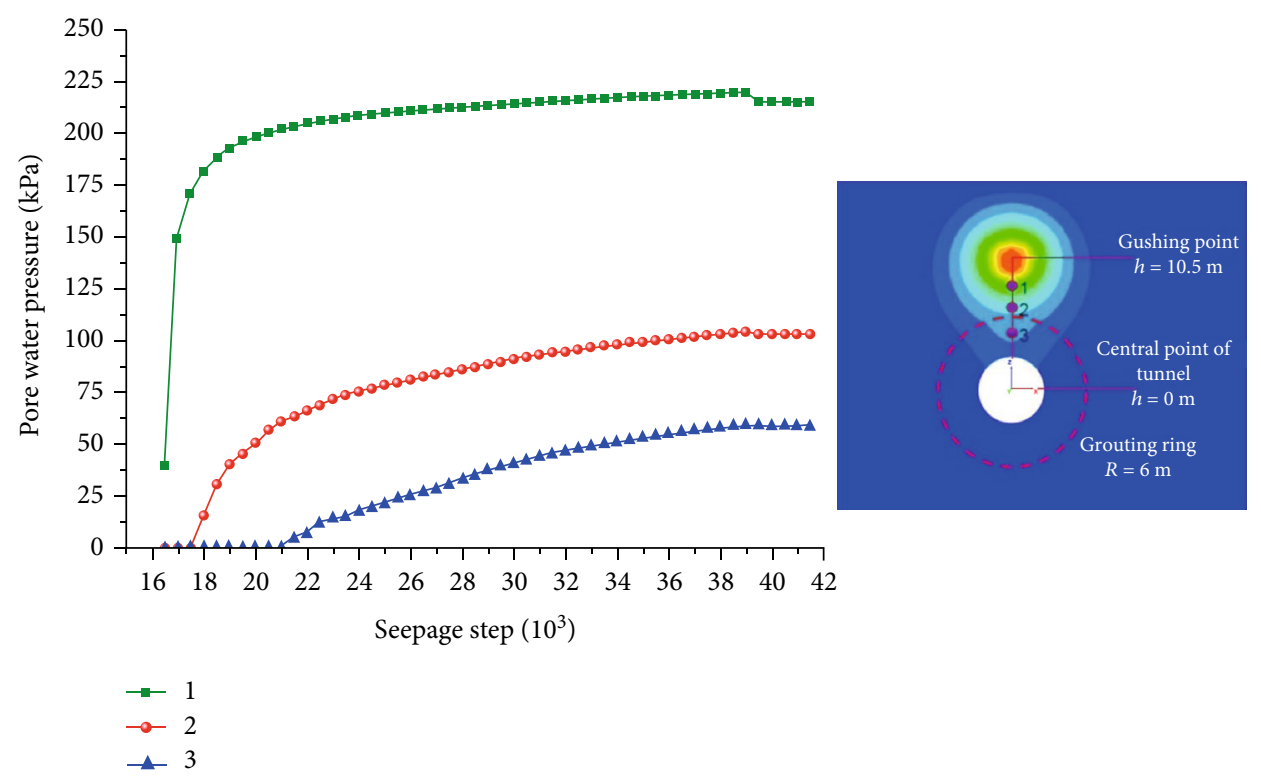

FIGURE 14: Seepage-time curve of axis measuring point of tunnel on surface of inrush.

$0.5 \mathrm{MPa}$. The diagram of grouting around the tunnel is shown in Figure 11.

3.3.2. Model Establishment. The model size is $80 \mathrm{~m}$ long, $80 \mathrm{~m}$ wide, and $57 \mathrm{~m}$ high. The left and right boundaries are symmetrically distributed according to the tunnel centerline. The left and right boundaries and the lower boundary are $40 \mathrm{~m}$ away from the tunnel center. The upper boundary is $14 \mathrm{~m}$ from the tunnel center. As for the boundary conditions, this model only considers gravity and water pressure. In the horizontal direction, the two sides of the model are constrained in the $X$ direction; in the vertical direction, the bottom is constrained in the $Z$ direction; and in the front and back directions, the front and back boundaries are constrained in the $Y$ direction. By applying the corresponding node pore pressure function to the nodes of the pipe opening, the state of the pipe outlet water can be simulated.

In addition, through the analysis of the grouting diffusion model of the tunnel in the rich water environment, the main factors influencing the grouting effect are the radius and the permeability coefficient of the grouting ring. Combined with the actual engineering situation of this study, the tunnel radius is $3 \mathrm{~m}$, the permeability coefficient of surrounding rock is $6.0 \times 10^{-6} \mathrm{~m} / \mathrm{s}$, and the water pressure is $0.25 \mathrm{MPa}$, which is equivalent to the water head of $25 \mathrm{~m}$. The ratio of the permeability coefficient between the surrounding rock and grouting reinforcement ring is $k$, and the thickness of the grouting ring is $c$. According to formula (9), the relationship curve between the water inflow of the tunnel and the thickness of the reinforcement ring is calculated, which is shown in Figure 12.

It can be seen from Figure 12 that with the increase of the thickness of the grouting ring, the water seepage of the tunnel decreases continuously. However, when $k \geq 150$ and $c \geq 3 \mathrm{~m}$, the effect of increasing the thickness of the grouting ring or reducing the permeability coefficient of the surrounding rock of the grouting ring on reducing the tunnel seepage is no longer obvious. Therefore, in the numerical simulation, considering the influence of soil erosion on the forming tunnel, grouting is carried out along the circular direction in the tunnel. The method of improving surrounding rock parameters is used to simulate the surrounding rock strengthened by grouting. Because of the 

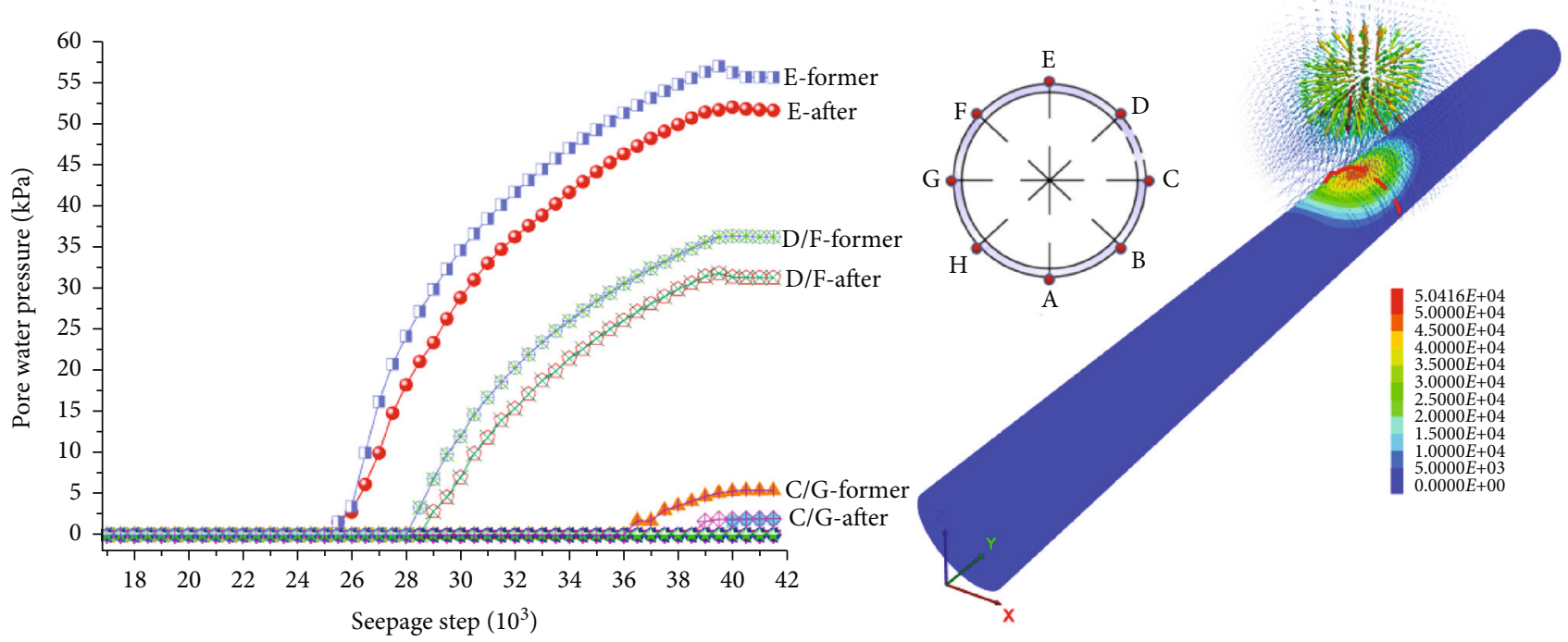

$$
\begin{array}{ll}
- \text { A-former } & -\square \text { E-former } \\
\nabla \text { B-former } & - \text { F-former } \\
\triangle \text { C-former } & + \text { G-former } \\
* \text { D-former } & \star \text { H-former } \\
- \text { A-after } & - \text { - E-after } \\
\rightarrow \text { B-after } & - \text { F-after } \\
- \text { C-after } & - \text { G-after } \\
\star \text { D-after } & \leftarrow \text { H-after }
\end{array}
$$

FIgURE 15: Time-dependent curve of water pressure at circumferential measuring points of the tunnel in the water source section.

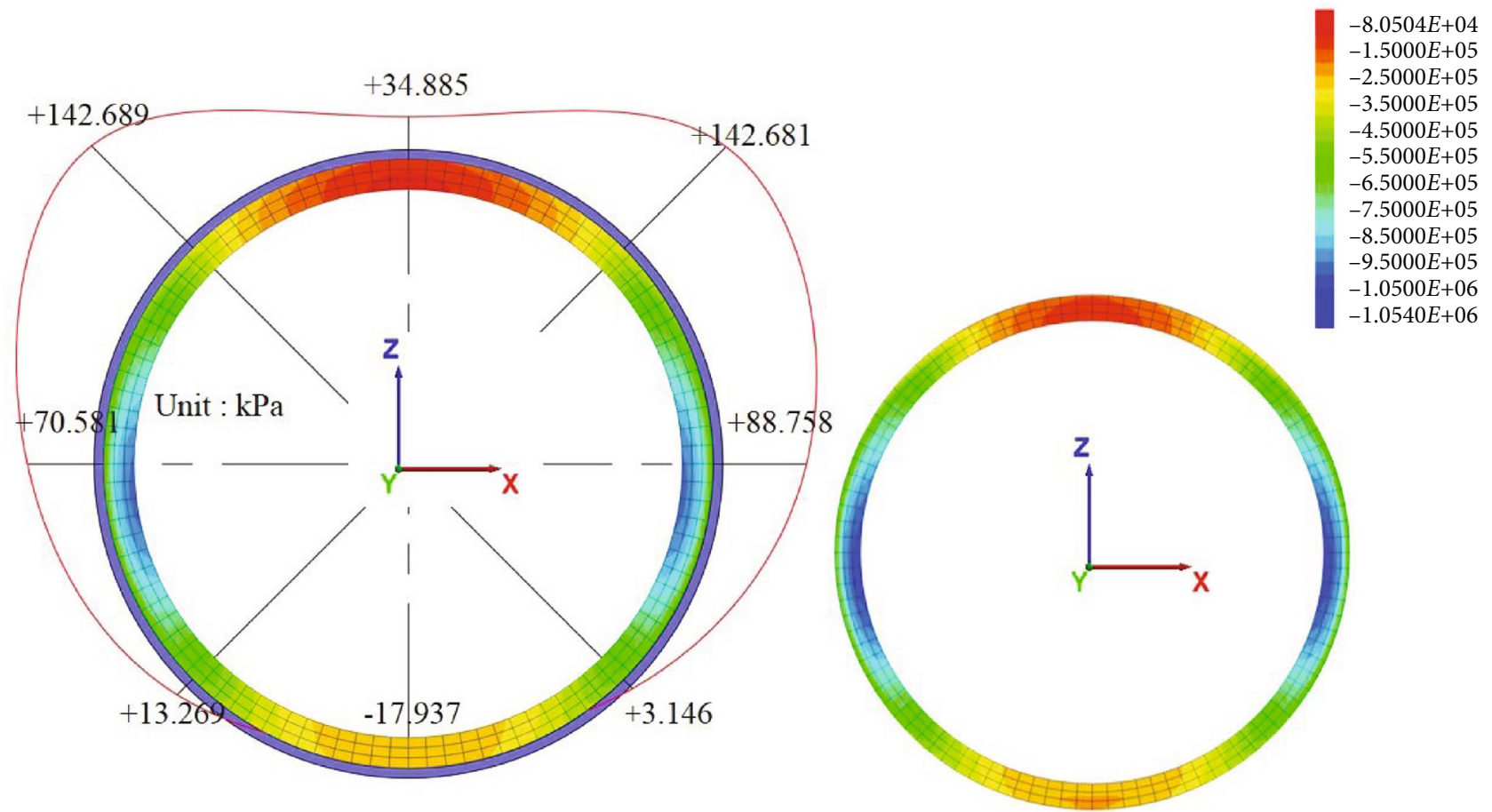

FIGURE 16: Maximum principal stress variation $(\mathrm{kPa})$.

relationship between water yield and grouting parameters in formula (9), in the numerical simulation, the grouting parameters are $k=150$ and $c=3 \mathrm{~m}$. The grouting can be equivalent to a reinforcement ring with a certain thickness after optimization of parameters outside the tunnel lining, as shown in Figure 13. Grouting parameters are shown in Table 4. 


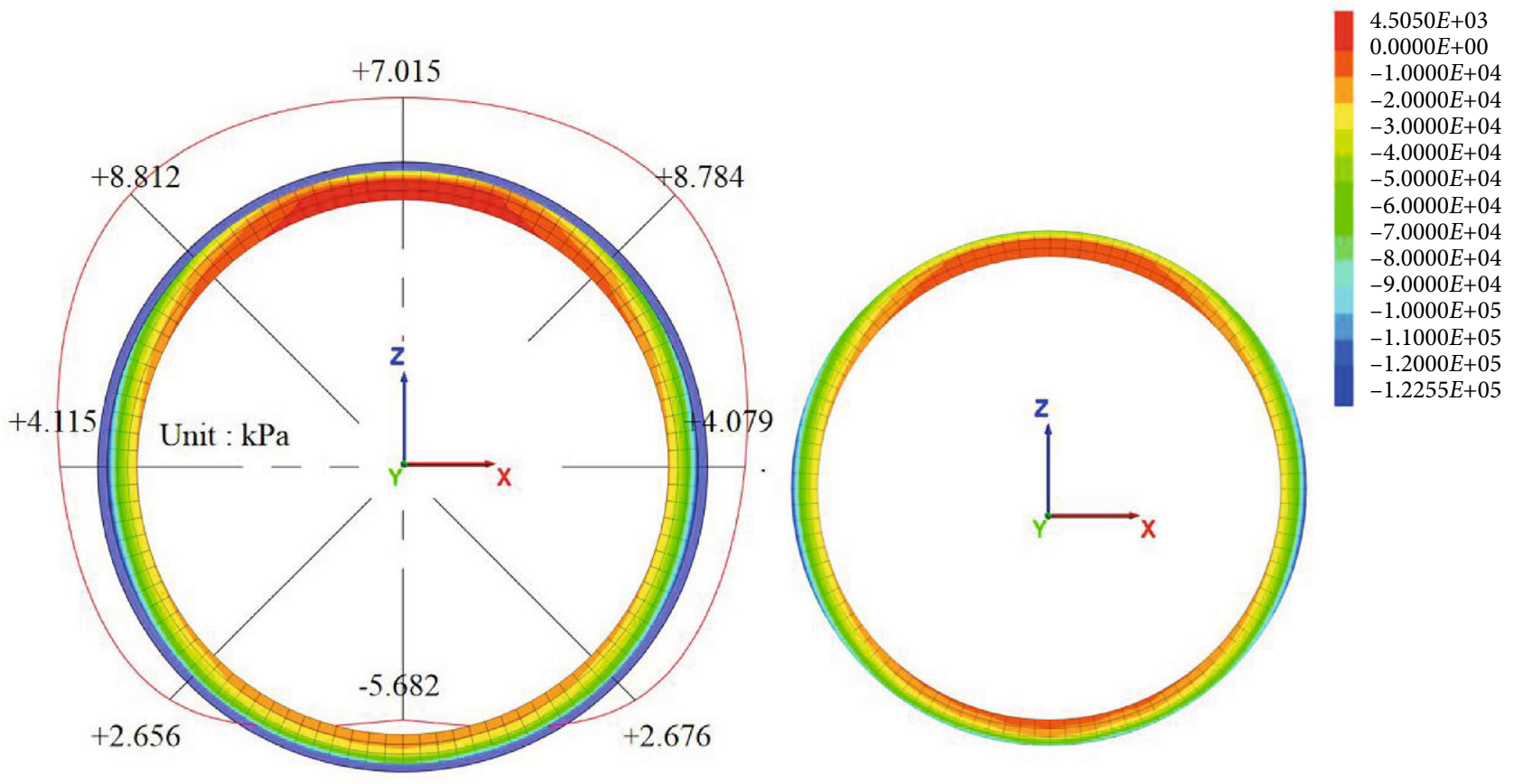

FIgURE 17: Minimum principal stress variation $(\mathrm{kPa})$.

TABLE 6: Analysis of principal stress change at annular measuring point of tunnel (kPa).

\begin{tabular}{llccccccccc}
\hline Measure point & & $\mathrm{A}$ & $\mathrm{B}$ & $\mathrm{C}$ & $\mathrm{D}$ & $\mathrm{E}$ & $\mathrm{F}$ & $\mathrm{G}$ & $\mathrm{H}$ \\
\hline \multirow{2}{*}{ Section \#1 } & Maximum principal stress & -17.94 & 3.15 & 88.76 & 142.68 & 34.89 & 142.69 & 70.58 & 13.27 \\
& Minimum principal stress & -5.68 & 2.68 & 4.08 & 8.78 & 7.01 & 8.81 & 4.11 & 2.66 \\
\hline \multirow{2}{*}{ Section \#2 } & Maximum principal stress & -15.74 & 11.90 & 60.93 & 95.94 & 6.70 & 95.96 & 56.27 & 1.21 \\
& Minimum principal stress & 31.23 & 1.95 & 0 & 0 & 0 & 1.95 & 31.24 & 17.70 \\
\hline \multirow{2}{*}{ Section \#3 } & Maximum principal stress & -9.60 & 8.02 & 27.09 & 27.44 & -10.54 & 27.37 & 27.05 & 8.08 \\
& Minimum principal stress & 34.67 & 41.65 & 30.33 & 20.31 & 36.59 & 14.96 & 18.44 & 6.62 \\
\hline
\end{tabular}

\subsubsection{Analysis of Calculation Results}

(1) Seepage Field. After water inrush, the seepage field of the surrounding rock changes, and a precipitation funnel area is formed above the tunnel vault. The influence area of the seepage field of the surrounding rock after grouting is smaller than that before grouting. When water enters the grouting range, the pore water pressure and the rate of change in the surrounding rock decrease obviously, and the influence area of the surrounding rock seepage field narrowed to the top of the tunnel vault. The analysis results are shown in Table 5.

Figure 14 shows the variation of water pressure with time along the tunnel centerline in the water source section. It can be seen from the graph that the water pressure of point 3 in the grouting ring is lower than that of points 1 and 2 outside the grouting ring, which indicates that the grouting reinforcement ring can effectively control the seepage in surrounding rock and reduce the range of water inrush.

Figure 15 is a time-dependent curve of water pressure at circumferential measuring points of the tunnel in the water source section. As can be seen from the figure, the maximum water pressure at the measured points of the tunnel vault is $52 \mathrm{MPa}$ after grouting and filling the stratum in the tunnel. Compared with the $56 \mathrm{MPa}$ before grouting, the water pressure of the tunnel circumferential measuring points is reduced. It shows that the grouting reinforcement ring can reduce the water pressure acting on the lining structure and the influence of the seepage pressure of local water source on the tunnel.

(2) Stress Field. Figure 16 is the maximum principal stress nephogram of the lining, and Figure 17 is the minimum. The curve in the figure represents the variation trend of the maximum principal stress and the minimum of lining in the process of local water source seepage. The positive value represents the increase in stress and the negative represents the decrease in stress. It can be seen that when the surrounding rock of the tunnel is reinforced by grouting, the variation range and peak area of the lining stress decrease, the maximum principal stress on the top of segment lining increases by $34.9 \mathrm{kPa}$, and the minimum increases by $8.8 \mathrm{kPa}$, which is lower than their increase before grouting, as shown in Table 6. 


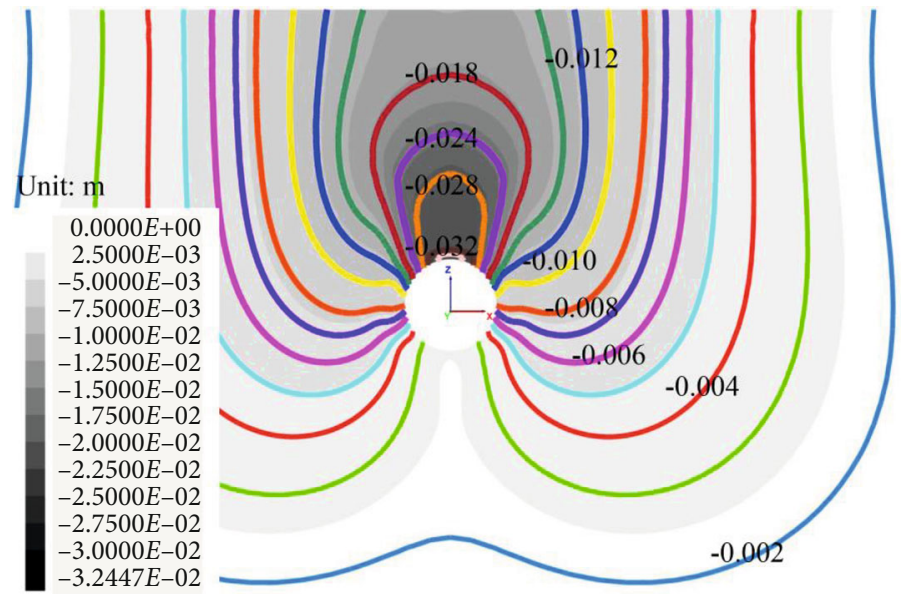

FIGURE 18: Distribution of vertical displacement of the surrounding rock before grouting.

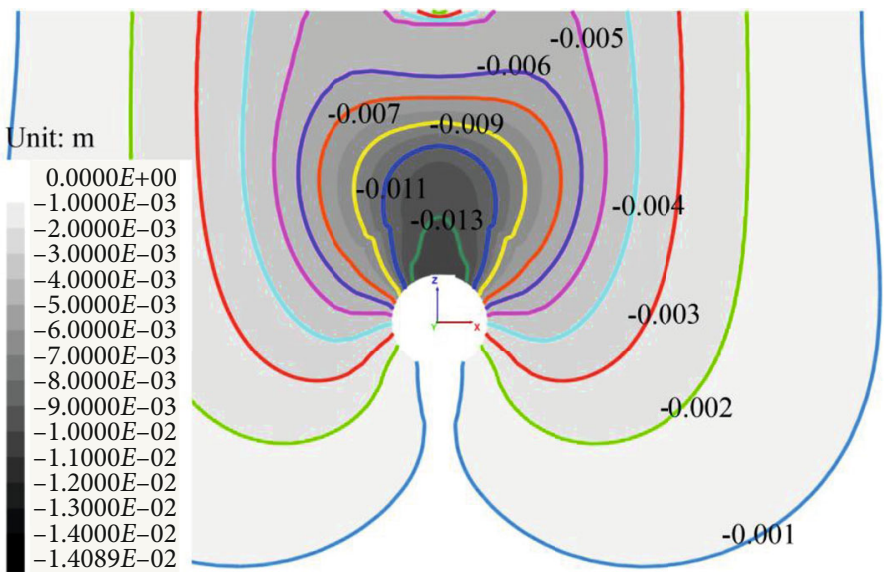

FIgURE 19: Distribution of vertical displacement of the surrounding rock after grouting.

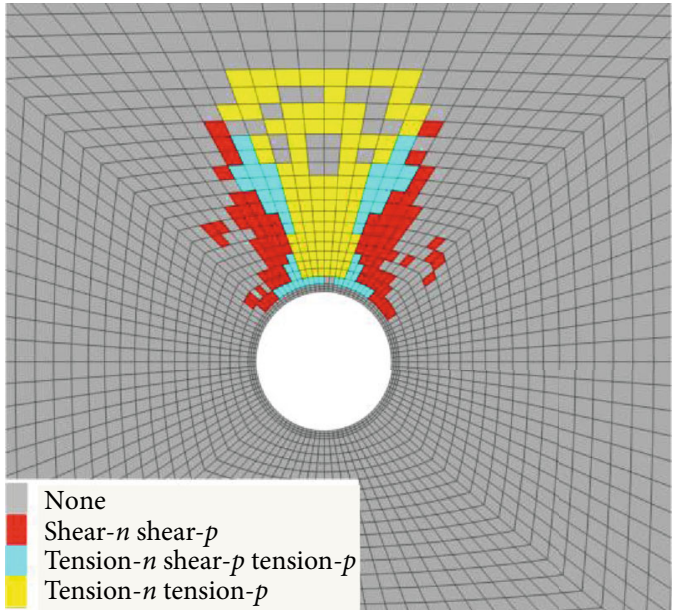

Figure 20: Distribution of the plastic zone before grouting.

(3) Displacement Field. Figures 18 and 19 show the distribution of the vertical displacement of the surrounding rock before and after grouting in the water source section. From the isoline distribution of displacement of the surrounding

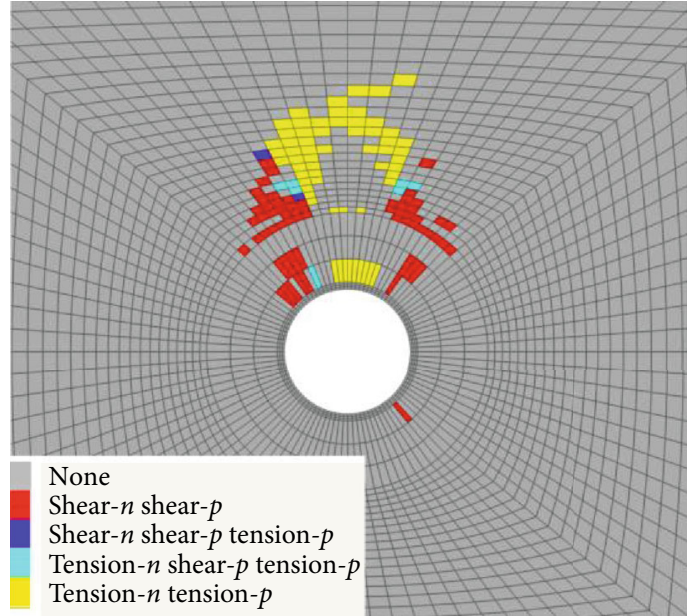

Figure 21: Distribution of the plastic zone after grouting.

rock in the figure, it can be seen that when the tunnel is reinforced by grouting, the maximum displacement of the surrounding rock occurs at the top of lining in the process of local water seepage. The displacement is $13 \mathrm{~mm}$, which is 


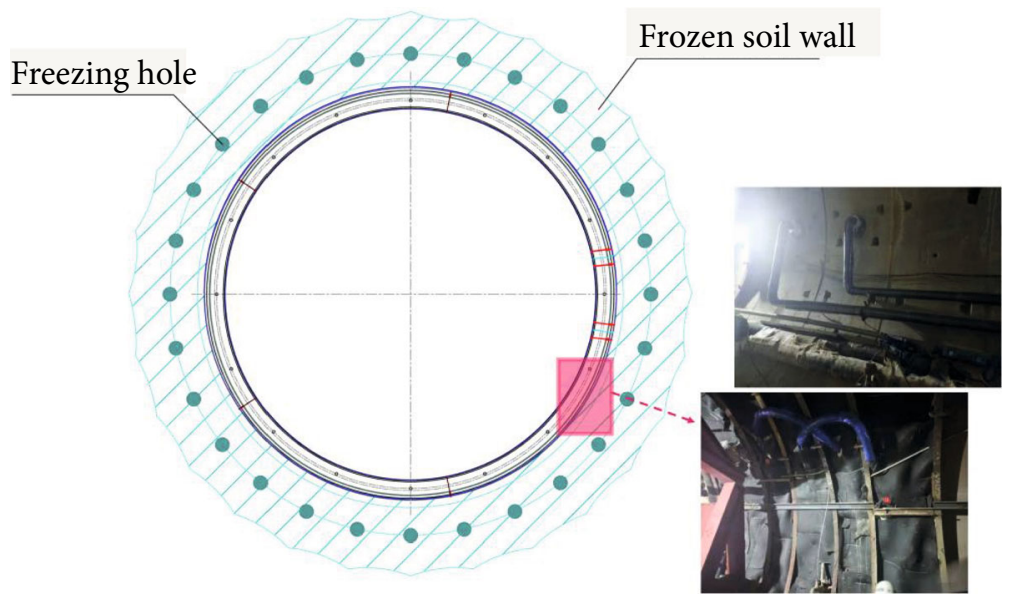

Figure 22: Construction diagram of the freezing method.

$19 \mathrm{~mm}$ less than that before grouting. The vertical displacement caused by local water seepage is lower than that before grouting. It indicates that grouting reinforcement can effectively reduce the displacement caused by local water seepage.

(4) Plastic Zone. Figures 20 and 21 show the distribution of the plastic zone in the surrounding rock of the water source section before and after grouting. It can be seen that after grouting reinforcement of the surrounding rock, the damaged area of the soil near the tunnel is effectively reduced due to the existence of the reinforcement ring. At this time, the tensile and shear failure areas near the top and shoulder of the segment are reduced. The area of the plastic zone produced after grouting is about $62 \%$ of that before grouting. The results show that grouting reinforcement can improve the plastic zone produced by local water seepage.

\section{Discussion and Analysis of Different Working Conditions}

At present, there are three methods to deal with the waterrich problem in the surrounding rock of the tunnel: grouting method, freezing method, and vacuum drainage method, among which the grouting method is more commonly used $[47,48]$. Taking the construction of a connecting passage in Xi'an metro as an example, the tunnel is located $24 \mathrm{~m}$ below Mingguang road. The stratum is rich in water and sand. Because of the high-water content of formation, to prevent water inrush and mud inrush during construction, a new technology of freezing construction is adopted. The construction diagram is shown in Figure 22. Freezing construction avoids the work of ground reinforcement and groundwater pumping, as well as the construction of ground retention.

The freezing method uses artificial refrigeration technology to freeze the water in the stratum and change the natural soil into frozen soil. The strength and stability of the surrounding rock are improved, and the connection between underground water and underground engineering is isolated, to carry out excavation construction under the protection of the frozen wall. Its essence is to use artificial refrigeration to temporarily change the nature of the rock and soil to consolidate the stratum. The freezing effect is shown in Figure 23. However, according to the principle of frost heave and thawing settlement, it will have a certain impact on the environment, and thawing settlement control needs to be strict. Otherwise, it will lead to differential settlement and longterm settlement of the structure. Also, the degree of freezing is seriously affected by groundwater. Under the action of dynamic water, the frozen soil will melt rapidly [49]. The geographic location of the project is less than $50 \mathrm{~m}$ from the Xibao high-speed railway line. Considering the safety of the high-speed rail operation and other factors, it is not allowed to drain groundwater in the $200 \mathrm{~m}$ range of high-speed rail lines, so the freezing method without drainage is finally adopted for construction $[50,51]$.

If the problem of the high-speed rail is not considered, the advantages and disadvantages of grouting ring reinforcement are shown in Figure 24, compared with the engineering cases discussed in the appeal.

According to the figure, compared with the grouting method, the freezing method has a shorter reinforcing time, and the erosion of groundwater after construction has not been solved, which may cause leakage of the tunnel lining. Grouting ring reinforcement can effectively plug groundwater, improve the bearing capacity of surrounding rock, and permanently solve the problems of groundwater and surrounding rock strength. Finally, considering the factors of economy and environmental protection, the grouting method is more reliable for the prevention and treatment of mud inrush and water inrush disasters.

\section{Conclusions and Recommendations}

To solve the water inrush of the metro tunnel under the surrounding pressure and water-soaking environment in the loess stratum, the grouting diffusion model in the loess stratum is established to quantify the relationship between the water inrush and related parameters. Based on a water inrush section of Xi'an metro, the effect of grouting reinforcement on the water inrush of the loess stratum is compared and 


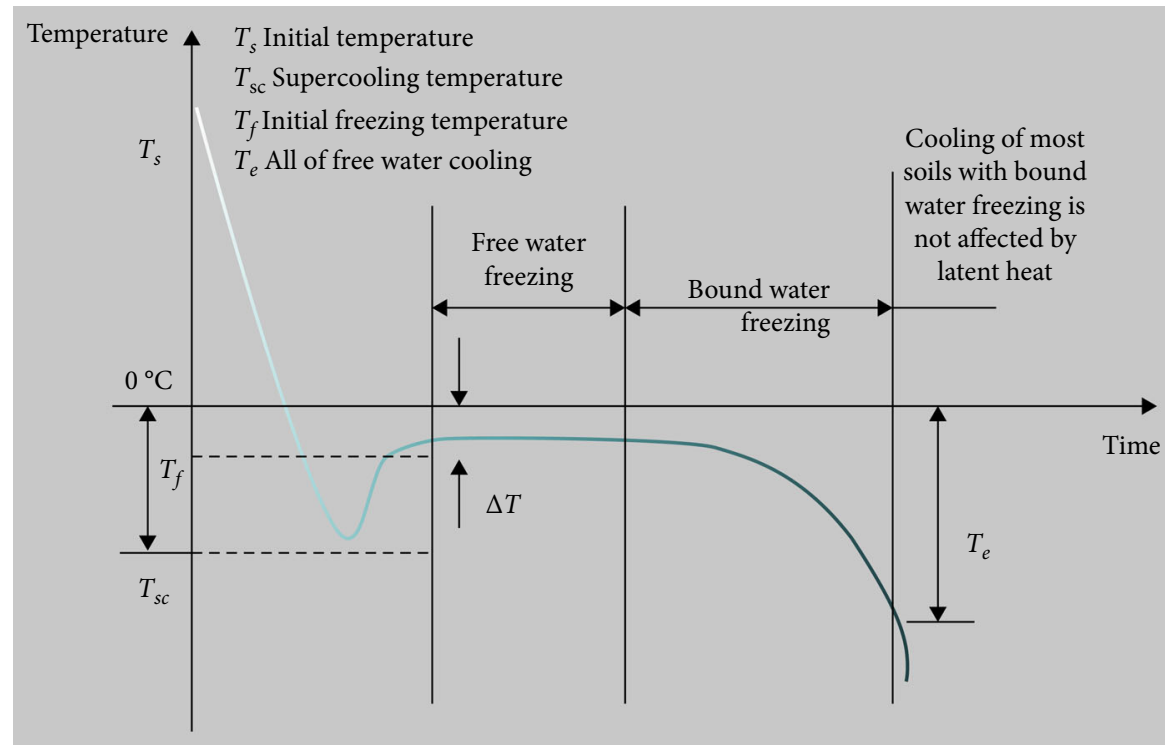

FiguRE 23: The relationship between soil temperature and time.

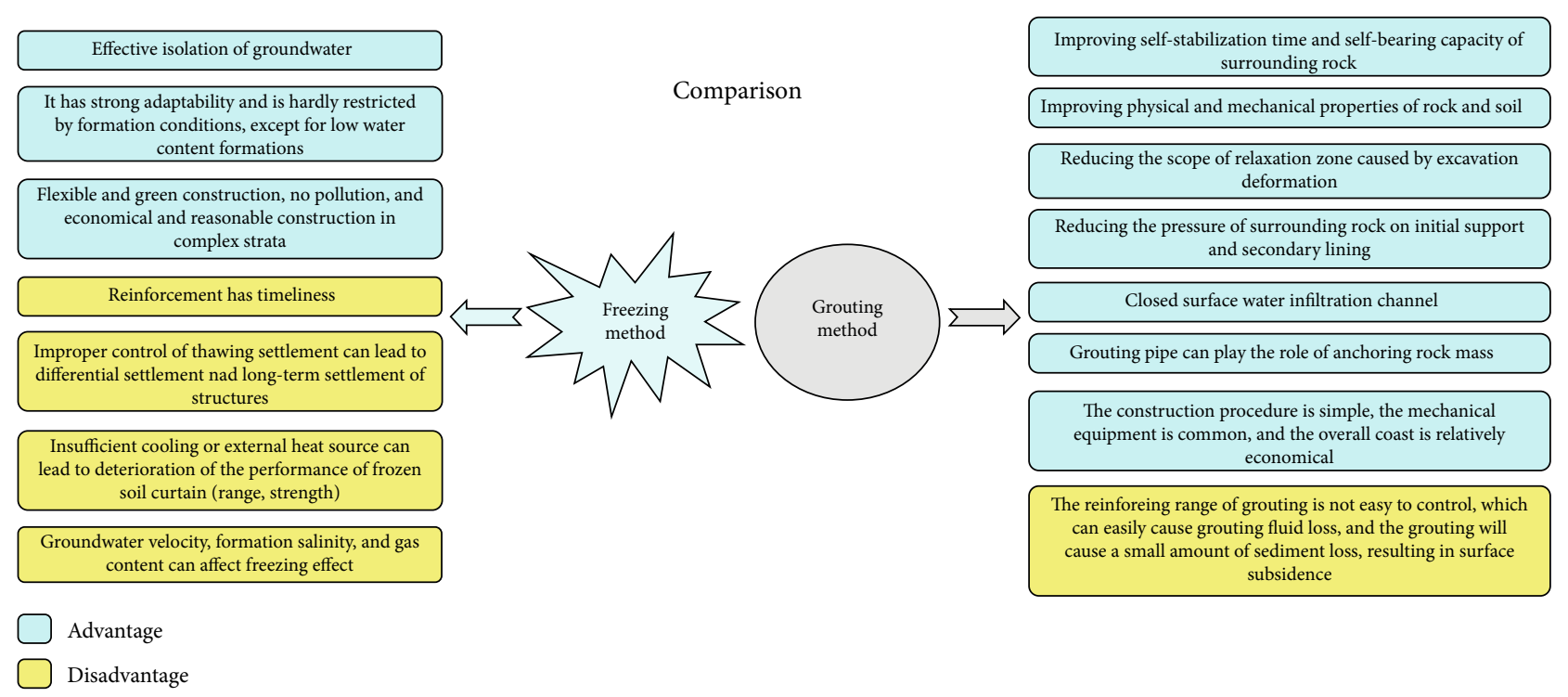

FIGURE 24: Comparison of two engineering treatment measures.

analyzed through on-site monitoring results and the establishment of a FLAC3D model. The following conclusions are drawn:

(1) Based on the formulas for calculating tunnel water inflow and lining external water pressure, the main factors affecting the grouting effect are the radius of the grouting ring and permeability coefficient of the grouting ring. According to the actual situation of the site project, with the increase of the thickness of the grouting ring, the seepage of the tunnel tends to decrease. When the ratio of the permeability coefficient between the surrounding rock and the grouting reinforcement ring is more than 150 and the thickness of the grouting ring is more than $3 \mathrm{~m}$, the effect of increasing the thickness or reducing the permeability coefficient of the surrounding rock of the grouting ring on reducing tunnel seepage is no longer obvious

(2) The numerical results show that after grouting reinforcement, the pore water pressure and the rate of change in the surrounding rock of the grouting ring have decreased obviously. The variation range and peak area of the lining stress are weakened. In the process of local water source seepage, the maximum displacement of the surrounding rock is reduced substantially, and the plastic zone of the surrounding rock is significantly reduced. In conclusion, after the treatment of circular grouting in the tunnel, the 
seepage range and the influence on the tunnel are reduced, and the grouting reinforcement has an obvious effect on controlling the surface settlement and reducing the tunnel displacement

(3) The safety prevention and treatment of the loess metro tunnel under the local dynamic water environment mainly adopts the grouting reinforcement scheme. The whole process should follow the treatment steps of "stable collapse, internal and external cooperation, grouting reinforcement, filling holes." Meanwhile, paying attention to real-time monitoring of grouting, the grouting effect evaluation, and analysis are carried out, and then an effective treatment system is established

\section{Conflicts of Interest}

The authors declare that they have no conflicts of interest.

\section{Acknowledgments}

This work is financially supported by the National Natural Science Foundation of China (Grant No. 51978066), the Key R\&D Plan of Shaanxi Province (No. 2020SF383), the Special Fund for Basic Scientific Research of Central Colleges of Chang'an University (No. 300102219117), and the Open Fund for Shaanxi Key Laboratory of Geotechnical and Underground Space Engineering (No. YT201905).

\section{References}

[1] D. Kaczorek, D. Puppe, J. Busse, and M. Sommer, "Effects of phytolith distribution and characteristics on extractable silicon fractions in soils under different vegetation - An exploratory study on loess," Geoderma, vol. 356, p. 113917, 2019.

[2] J. L. Qiu, Y. Q. Lu, J. X. Lai et al., "Experimental study on the effect of water gushing on loess metro tunnel," Environmental Earth Sciences, vol. 79, no. 11, 2020.

[3] D. Wolf, K. Ryborz, T. Kolb et al., "Origins and genesis of loess deposits in central Spain, as indicated by heavy mineral compositions and grain-size variability," Sedimentology, vol. 66, no. 3, pp. 1139-1161, 2019.

[4] S. M. Haeri, A. Khosravi, A. A. Garakani, and S. Ghazizadeh, "Effect of soil structure and disturbance on hydromechanical behavior of collapsible loessial soils," International Journal of Geomechanics, vol. 17, no. 1, article 04016021, 2016.

[5] J. L. Qiu, Y. Q. Lu, J. X. Lai, C. X. Guo, and K. Wang, "Failure behavior investigation of loess metro tunnel under local-highpressure water environment," Engineering Failure Analysis, vol. 112, no. 4, 2020.

[6] M. S. Nouaouria, M. Guenfoud, and B. Lafifi, "Engineering properties of loess in Algeria," Engineering Geology, vol. 99, no. 1-2, pp. 85-90, 2008.

[7] E. Derbyshire, "Geological hazards in loess terrain, with particular reference to the loess regions of China," Earth-Science Reviews, vol. 54, no. 1-3, pp. 231-260, 2001.

[8] J. Qiu, Y. Qin, J. Lai et al., "Structural response of the metro tunnel under local dynamic water environment in loess strata," Geofluids, vol. 2019, Article ID 8541959, 16 pages, 2019.
[9] L. X. Wang, E. L. Ma, H. Li et al., "Tunnelling induced settlement and treatment techniques for a loess metro in Xi'an," Advances in Civil Engineering, vol. 2020, Article ID 1854813, 16 pages, 2020.

[10] H. Sun, Q. Wang, P. Zhang, Y. Zhong, and X. Yue, "Spatialtemporal Characteristics of Tunnel Traffic Accidents in China from 2001 to Present," Advances in Civil Engineering, vol. 2019, Article ID 4536414, 12 pages, 2019.

[11] Y. Zhang, X. Weng, Z. Song, and Y. Sun, "Modeling of loess soaking induced impacts on a metro tunnel using a water soaking system in centrifuge," Geofluids, vol. 2019, Article ID 5487952, 17 pages, 2019.

[12] X. L. Wang, S. Y. He, J. X. Lai, and R. S. Garnes, "Karst geology and mitigation measures for hazards during metro system construction in Wuhan, China," Natural Hazards, vol. 102, no. 3, 2020.

[13] W. C. Cheng, G. Li, N. Liu, J. Xu, and S. Horpibulsuk, "Recent massive incidents for subway construction in soft alluvial deposits of Taiwan: a review," Tunnelling and Underground Space Technology, vol. 96, p. 103178, 2020.

[14] X. X. Liu, S. L. Shen, Y. S. Xu, and Z. Y. Yin, “Analytical approach for time-dependent groundwater inflow into shield tunnel face in confined aquifer," International Journal for Numerical and Analytical Methods in Geomechanics, vol. 42, no. 4, pp. 655-673, 2018.

[15] X. X. Liu, S. L. Shen, A. Zhou, and Y. S. Xu, "Evaluation of foam conditioning effect on groundwater inflow at tunnel cutting face," International Journal for Numerical and Analytical Methods in Geomechanics, vol. 43, no. 2, pp. 463-481, 2019.

[16] Y. X. Wu, S. L. Shen, H. M. Lyu, and A. Zhou, "Analyses of leakage effect of waterproof curtain during excavation dewatering," Journal of Hydrology, vol. 583, article 124582, 2020.

[17] G. Modoni, L. Wanik, C. M. Maria et al., "Strength of sandy and clayey soils cemented with single and double fluid jet grouting," Soils and Foundations, vol. 59, no. 4, pp. 942-954, 2019.

[18] D. M. Zhang, Z. S. Liu, R. L. Wang, and D. M. Zhang, "Influence of grouting on rehabilitation of an over-deformed operating shield tunnel lining in soft clay," Acta Geotechnica, vol. 14, no. 4, pp. 1227-1247, 2019.

[19] M. Akin, I. Akkaya, M. K. Akin, A. Özvan, and Y. Ak, "Impact of jet-grouting pressure on the strength and deformation characteristics of sandy and clayey soils in the compression zone," KSCE Journal of Civil Engineering, vol. 23, no. 8, pp. 33403352, 2019.

[20] B. Gong, Y. Jiang, K. Okatsu, X. Wu, J. Teduka, and K. Aoki, "The seepage control of the tunnel excavated in high-pressure water condition using multiple times grouting method," Processes, vol. 6, no. 9, p. 159, 2018.

[21] J. Yang, Y. Cheng, and W. Chen, "Experimental study on diffusion law of post-grouting slurry in sandy soil," Advances in Civil Engineering, vol. 2019, Article ID 3493942, 11 pages, 2019.

[22] A. Apaydin, N. Korkmaz, and D. Ciftci, "Water inflow into tunnels: assessment of the Gerede water transmission tunnel (Turkey) with complex hydrogeology," Quarterly Journal of Engineering Geology and Hydrogeology, vol. 52, no. 3, pp. 346-359, 2019.

[23] M. Bai, Y. Chen, C. Wang, X. Li, and G. Tian, "Radar spectral analysis and evaluation of the effect of grouting treatment in karst caves and soil caves," Environmental Earth Sciences, vol. 77, no. 24, p. 795, 2018. 
[24] Z. Li, S. Li, H. Liu, Q. Zhang, and Y. Liu, "Experimental study on the reinforcement mechanism of segmented split grouting in a soft filling medium," Processes, vol. 6, no. 8, p. 131, 2018.

[25] K. Wu, Z. Shao, C. Li, and S. Qin, “Theoretical investigation to the effect of bolt reinforcement on tunnel viscoelastic behavior," Arabian Journal for Science and Engineering, vol. 45, no. 5, pp. 3707-3718, 2020.

[26] X. Yu, G. Xing, and Z. Chang, "Flexural behavior of reinforced concrete beams strengthened with near-surface mounted 7075 aluminum alloy bars," Journal of Building Engineering, vol. 31, Article ID 101393, 2020.

[27] L. Cao, D. Zhang, Q. Fang, and L. Yu, "Movements of ground and existing structures induced by slurry pressure-balance tunnel boring machine (SPB TBM) tunnelling in clay," Tunnelling and Underground Space Technology, vol. 97, article 103278, 2020.

[28] D. M. Zhang, Z. K. Huang, R. L. Wang, J. Y. Yan, and J. Zhang, "Grouting-based treatment of tunnel settlement: practice in Shanghai," Tunnelling and Underground Space Technology, vol. 80, pp. 181-196, 2018.

[29] P. Li, H. Zou, F. Wang, and H. Xiong, "An analytical mechanism of limit support pressure on cutting face for deep tunnels in the sand," Computers and Geotechnics, vol. 119, article 103372, 2020.

[30] Ø. Dammyr, "Pressurized TBM-shield tunneling under the subsidence sensitive grounds of Oslo: possibilities and limitations," Tunnelling and Underground Space Technology, vol. 66, pp. 47-55, 2017.

[31] T. Guo, Z. Cao, Z. Zhang, and A. Li, "Numerical simulation of floor vibrations of a metro depot under moving subway trains," Journal of Vibration and Control, vol. 24, no. 18, pp. 4353-4366, 2017.

[32] S. Wang, X. Jiang, and Y. Bai, “The influence of hand hole on the ultimate strength and crack pattern of shield tunnel segment joints by scaled model test," Frontiers of Structural and Civil Engineering, vol. 13, no. 5, pp. 1200-1213, 2019.

[33] H. Jin, K. Yu, S. Zhou, Q. Gong, and H. Yan, "Performance assessment of shield tunnel damaged by shield shell extrusion during construction," International Journal of Civil Engineering, vol. 17, no. 7, pp. 1015-1027, 2019.

[34] L. Jin-long, O. Hamza, K. S. Davies-Vollum, and L. Jie-qun, "Repairing a shield tunnel damaged by secondary grouting," Tunnelling and Underground Space Technology, vol. 80, pp. 313-321, 2018.

[35] F.-Y. Wang, M. L. Zhou, D. M. Zhang, H. W. Huang, and D. Chapman, "Random evolution of multiple cracks and associated mechanical behaviors of segmental tunnel linings using a multiscale modeling method," Tunnelling and Underground Space Technology, vol. 90, pp. 220-230, 2019.

[36] Z. Zhou, Y. Dong, P. Jiang, D. Han, and T. Liu, "Calculation of pile side friction by multiparameter statistical analysis," Advances in Civil Engineering, vol. 2019, Article ID 2638520, 12 pages, 2019.

[37] H. Wu, Y. J. Zhong, W. Xu, W. Shi, and X. H. Shi, "Experimental investigation of ground and air temperature fields of a coldregion road tunnels in NW China," Advances in Civil Engineering, vol. 2020, Article ID 4732490, 13 pages, 2020.

[38] W. C. Cheng, Z. P. Song, W. Tian, and Z. F. Wang, "Shield tunnel uplift and deformation characterisation: a case study from Zhengzhou metro," Tunnelling and Underground Space Technology, vol. 79, pp. 83-95, 2018.
[39] P. Li, F. Wang, L. Fan, H. Wang, and G. Ma, "Analytical scrutiny of loosening pressure on deep twin-tunnels in rock formations," Tunnelling and Underground Space Technology, vol. 83, pp. 373-380, 2019.

[40] H. Wu, C. Yao, C. Li et al., "Review of application and innovation of geotextiles in geotechnical engineering," Materials, vol. 13, no. 7, article 1774, 2020.

[41] K. Wu, Z. Shao, S. Qin, and B. Li, "Determination of deformation mechanism and countermeasures in silty clay tunnel," Journal of Performance of Constructed Facilities, vol. 34, no. 1, article $04019095,2020$.

[42] Z.-F. Wang, S. L. Shen, and G. Modoni, "Enhancing discharge of spoil to mitigate disturbance induced by horizontal jet grouting in clayey soil: theoretical model and application," Computers and Geotechnics, vol. 111, pp. 222-228, 2019.

[43] Z. Zhang and F. Sun, "Thermal-mechanical coupled analysis for tunnel lining with circular openings," Tunnelling and Underground Space Technology, vol. 97, article 103192, 2020.

[44] Y. Liu and H. Lai, "Load characteristics of tunnel lining in flooded loess strata considering loess structure," Advances in Civil Engineering, vol. 2019, Article ID 3731965, 13 pages, 2019.

[45] X. Nie, S. Feng, Z. Shudu, and G. Quan, "Simulation study on the dynamic ventilation control of single head roadway in high-altitude mine based on thermal comfort," Advances in Civil Engineering, vol. 2019, Article ID 2973504, 12 pages, 2019.

[46] Z. Zhang, K. Zhang, W. Dong, and B. Zhang, "Study of rockcutting process by disc cutters in mixed ground based on Three-dimensional particle flow model," Rock Mechanics and Rock Engineering, vol. 53, no. 6, 2020.

[47] X. Guo, J.-R. Chai, Y. Qin, Z.-G. Xu, Y.-N. Fan, and X.-W. Zhang, "Mechanism and treatment technology of three water inrush events in the Jiaoxi river tunnel in Shaanxi, China," Journal of Performance of Constructed Facilities, vol. 33, no. 1, article 04018098, 2019.

[48] Z. Song, G. Shi, B. Zhao, K. Zhao, and J. Wang, "Study of the stability of tunnel construction based on double-heading advance construction method," Advances in Mechanical Engineering, vol. 12, no. 1, Article ID 168781401989696, 2020.

[49] M. A. Alzoubi, A. Nie-Rouquette, and A. P. Sasmito, "Conjugate heat transfer in artificial ground freezing using enthalpyporosity method: experiments and model validation," International Journal of Heat and Mass Transfer, vol. 126, pp. 740752, 2018.

[50] X. Liu, Q. Fang, D. Zhang, and Z. Wang, "Behaviour of existing tunnel due to new tunnel construction below," Computers and Geotechnics, vol. 110, pp. 71-81, 2019.

[51] L. X. Wang, S. S. Xu, J. L. Qiu et al., “Automatic monitoring system in underground engineering construction: Review and prospect," Advances in Civil Engineering, Article ID 3697253, 2020. 